\title{
Development and Evaluation of a Patient Decision Aid for the West Virginia Physician Order for Scope of Treatment (POST)
}

Jarred V. Gallegos

Follow this and additional works at: https://researchrepository.wvu.edu/etd

\section{Recommended Citation}

Gallegos, Jarred V., "Development and Evaluation of a Patient Decision Aid for the West Virginia Physician Order for Scope of Treatment (POST)" (2017). Graduate Theses, Dissertations, and Problem Reports. 5641.

https://researchrepository.wvu.edu/etd/5641

This Thesis is protected by copyright and/or related rights. It has been brought to you by the The Research Repository @ WVU with permission from the rights-holder(s). You are free to use this Thesis in any way that is permitted by the copyright and related rights legislation that applies to your use. For other uses you must obtain permission from the rights-holder(s) directly, unless additional rights are indicated by a Creative Commons license in the record and/ or on the work itself. This Thesis has been accepted for inclusion in WVU Graduate Theses, Dissertations, and Problem Reports collection by an authorized administrator of The Research Repository @ WVU. For more information, please contact researchrepository@mail.wvu.edu. 
Development and Evaluation of a Patient Decision Aid for the West Virginia Physician Order for Scope of Treatment (POST)

\author{
Jarred V Gallegos, M.A.
}

Thesis submitted to the Eberly College of Arts and Sciences at West Virginia University in partial fulfillment of the requirements for the degree of

Master of Science in Psychology

Barry Edelstein, Ph.D., Chair

Nicholas A. Turiano, Ph.D.

JoNell Strough, Ph.D.

Alvin Moss, M.D.

Department of Psychology

Morgantown, West Virginia

2017

Keywords: End-of-life, medical decision, decision aid Copyright 2017 Jarred V. Gallegos 


\title{
ABSTRACT \\ Development and Evaluation of a Patient Decision Aid for the West Virginia Physician Order for Scope of Treatment (POST)
}

\author{
Jarred V. Gallegos
}

Decision aids have been shown to be helpful for patients making medical decisions. The use of decision aids can increase patient knowledge, decrease decisional conflict, and increase overall satisfaction with the treatment decision made. The purpose of the study was to develop and evaluate a novel video decision aid for the West Virginia Physician Orders for Scope of Treatment (POST). There are no known decision aids developed to assist patients completing POST forms, thus there is a paucity of research investigating the nature, quality, and outcomes of the decision-making process of patients completing a POST form. Fifty English-speaking, community-dwelling older adults $(65+)$ were recruited to participate in the study. The study employed a pre/post repeated measures design and used three measures to evaluate the effectiveness of the decision aid: Decisional Conflict Scale (DCS), Satisfaction with Decision Scale (SWD), and an 18-item Knowledge Questionnaire. Participants were given a case vignette that provided hypothetical medical information for the purpose of making treatment decisions and completing the study measures. Additional analyses were conducted to investigate the role of personality traits in the prediction of decision-making variables: decisional conflict, satisfaction with decision, and preferred role in decision-making. Results indicated significant increases in participant knowledge and decisional satisfaction, and significantly lower levels of decisional conflict after viewing the video-aid. Participants also rated feeling comfortable viewing the aid, that the aid was helpful, and that they would recommend the aid to a friend or family member. Higher levels of neuroticism significantly predicted a collaborative compared to a passive style. No personality trait uniquely accounted for variance in decisional conflict or satisfaction. Results show that in an experimentally controlled, non-patient sample, a decision aid can be useful in improving decisional outcomes for individuals making POST medical decisions. Findings from the study provide the first evidence to support the use of decision aids with the POST form. Personality traits were found to influence decisional outcomes, but further research is required to investigate the relation. 


\section{Table of Contents}

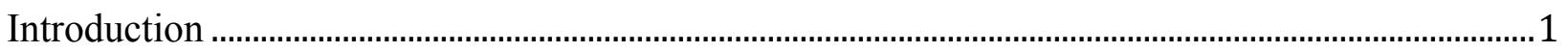

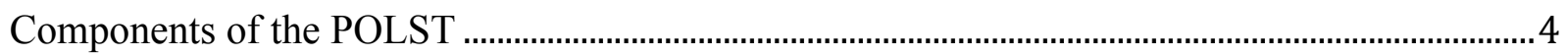

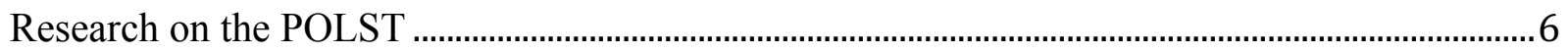

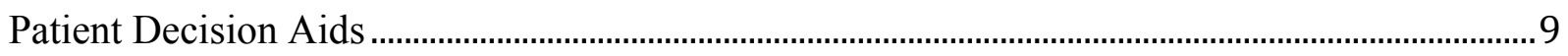

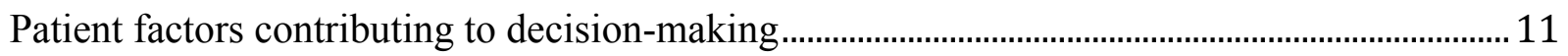

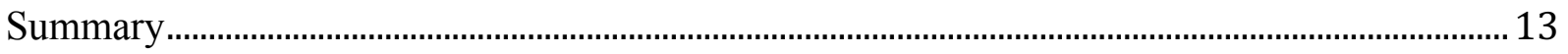

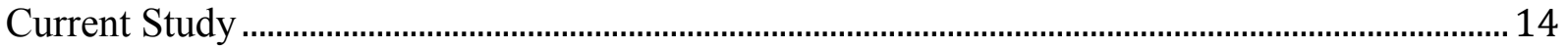

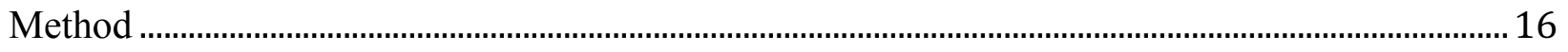

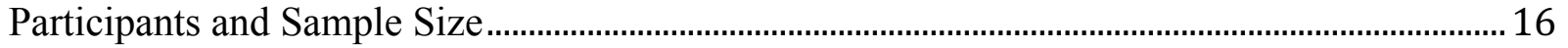

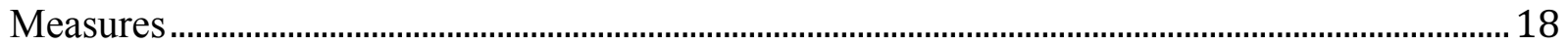

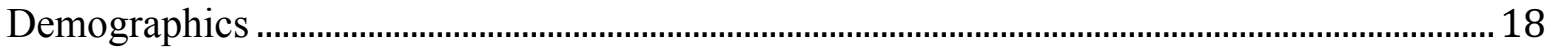

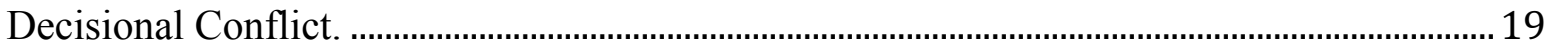

Satisfaction with Decision................................................................................................................ 19

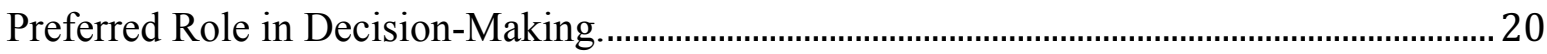

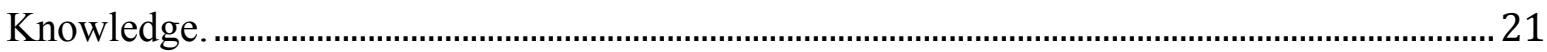

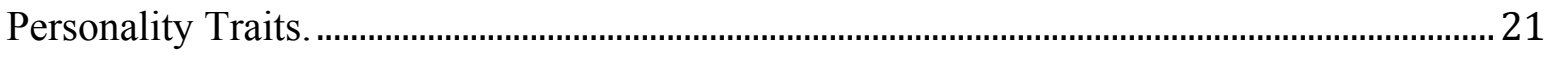

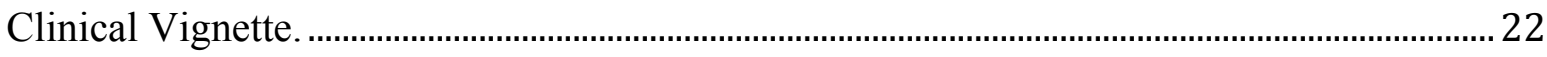

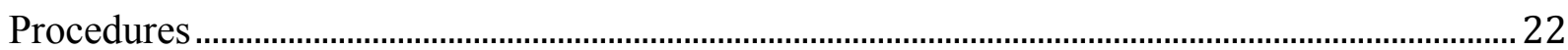

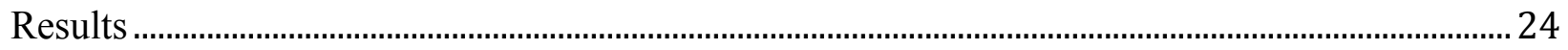

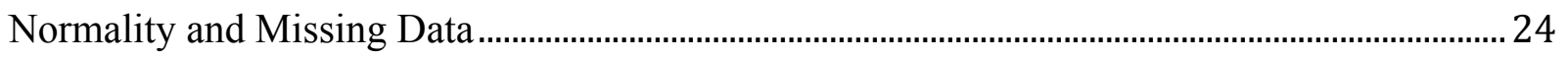

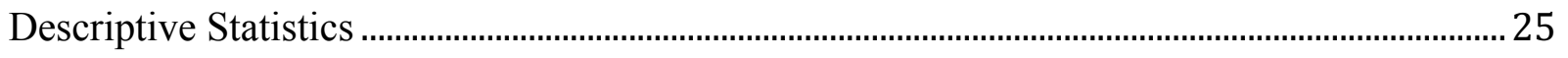

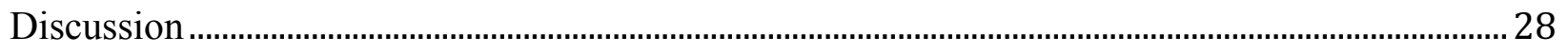

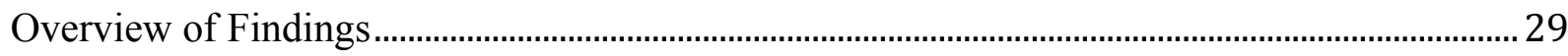

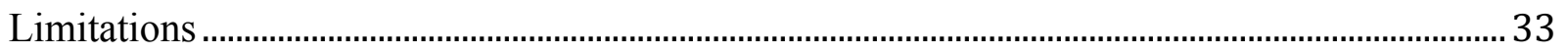

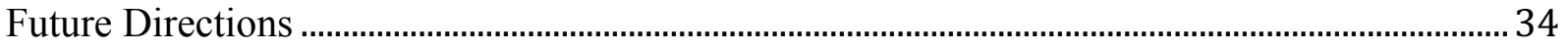

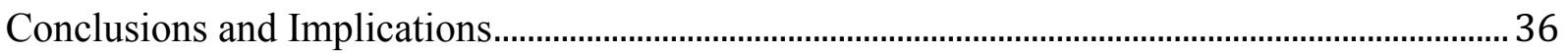

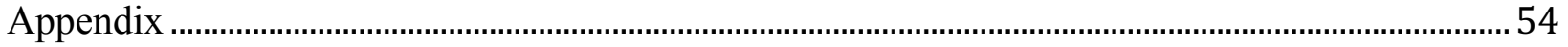


Development and Evaluation of a Patient Decision Aid for the West Virginia Physician Order for Scope of Treatment (POST)

In recent years there has been a concerted effort to improve end-of-life care. In an effort to ensure or improve the quality of end of life care, the Institute of Medicine (2015) recommended that clinicians engage in "high-quality" conversations with patients regarding endof-life care and revisit these discussions over time. More specifically, the report recommends the process of shared decision-making when making end-of-life decisions. Shared decision-making is the process of healthcare decisions being made through collaboration between the patient and healthcare provider (Stacey et al., 2014). Shared decision-making requires at least two participants (e.g. physician and patient) sharing relevant information in the context of the decision-making process. The process results in a treatment decision with which both parties are satisfied (Charles et al., 1997). Shared decision-making incorporates principles of informed choice and patient autonomy, which emphasize patient understanding of treatment options and the active role of the patient in the decision-making process. Shared decision-making is particularly important when making medical decisions where there may not be a clear "best choice" among treatment options (O’Connor et al., 2009). Decisions without a best choice are referred to as "preference-sensitive," which incorporates patient values along with medical information (Stacey et al., 2014). These types of decisions are common when discussing end-oflife treatment, such as decisions for life-prolonging interventions.

Shared decision-making is a central element of a relatively new form of documentation of patient end-of-life choice, which is termed the Physician Order for Life-Sustaining Treatment (POLST). The POLST website provides detailed information about the form and available resources (http://polst.org/about-the-national-polst-paradigm/what-is-polst/). A POLST is a 
physician's order contained in a form that is completed following discussions between the patient and health care providers in which the patient conveys his or her wishes for lifesustaining medical interventions near end-of-life (i.e., CPR/DNR, symptom management, medically administered fluids and nutrition). The POLST and related documents originated during the early 1990's in Oregon in response to concerns that patient preferences were not being consistently honored during end-of-life care. Completion of the POLST emphasizes shared decision-making between patient and provider, and family members or health care proxies.

There are currently several variations of the POLST form in use throughout the United States. Depending upon the state, it can be referred to as a Medical Order for Life-Sustaining Treatment (MOLST), Physician Order for Scope of Treatment (POST), or Medical Order for Scope of Treatment (MOST). These variations, as well as some others, are included under the umbrella term of POLST paradigm, which is the over-arching approach to end-of-life care that emphasizes discussion of patient values with family members and health care providers, as well as documentation of treatment preferences to ensure patient wishes are honored. The National POLST Paradigm Task Force serves as a governing committee for establishing quality standards for POLST programs, and assists states during their development of POLST programs. States must demonstrate their individual program meets the National POLST Paradigm Task Force guidelines in order to be endorsed by the task force. After submitting application form and presenting a POLST form and program to the National POLST Paradigm Task Force, a state is recognized as a "developing program." State programs are "endorsed" by the task force when the state has begun statewide implementation of a POLST form and have addressed legal and 
regulatory issues associated with the POLST. As of June $23^{\text {rd }}, 2017,25$ states have POLST programs endorsed by the task force.

The POLST paradigm does not replace advance directives or living wills. The use of the POLST paradigm differs from typical advance directives because it is not designed for use with the general population. Instead, the POLST paradigm is used with individuals with life-limiting terminal illness. The POLST paradigm complements traditional methods of advance care planning by translating treatment preferences into a clear and actionable physician order that is carried out across various settings of care, including long-term care, home health, hospice, and assisted living facilities (Caprio, 2014; Fromme, Zive, Schmidt, Olszewski, \& Tolle, 2012; Hammes, Rooney, Gundrum, Hickman, \& Hager, 2012). The completed medical order accompanies a patient following admission/discharge from one care facility to another, such as discharge from hospital to an assisted living facility, or the patient's home. A completed POLST offers additional benefits to traditional advance directives in that it is stored in a patient's medical chart and is designed to be easily accessible by medical personnel during an emergency. Further, some states (e.g., Oregon, New York, West Virginia, \& Idaho) have established online registries to store these forms so that they can be more easily accessed.

As previously noted, a POLST form is to be completed only with seriously ill or frail patients, or an individual with an advanced life-limiting illness. A guiding question for health care providers that indicates the need for standing medical orders is, "Would you be surprised if the patient died in the next year". If the provider's answer is "no," then completion of a POLST form with the patient is recommended. In addition, execution or updating of a POLST is recommended at the time of a patient's admission to a care facility, following a change in patient 
health status, when patient's treatment preferences change, and following hospice enrollment (Caprio, Rollins, \& Roberts, 2012). For healthy patients or individuals not receiving current endof-life care, traditional advance directives would be appropriate.

There are legal guidelines based on each state using the POLST paradigm, specifying what signatures are required for the POLST to become valid. Certain states only permit physician's signatures to validate a POLST, while others accept signatures from nurse practitioners or physician's assistants (Pope \& Hexum, 2012; Vo et al., 2011).

Despite laws establishing who must sign to validate the POLST, most states do not have guidelines for which medical team member prepares the POLST with patients. Research by Hickman and colleagues (2004) has revealed the involvement of a wide range of personnel in preparation of the POLST, including social workers, physicians, and nursing staff. Although lacking medical degrees, there is support for the use of social workers in preparing POLST forms (Bomba, Morrissey, \& Leven, 2011), particularly in situations where physicians are available to address relevant medical questions (Caprio, Rollins, \& Roberts, 2012).

\section{Components of the POLST}

POLST paradigm forms are typically separated into distinct sections that divide types of medical interventions as well as patient/provider signatures and consents. Patients' treatment wishes are documented by checking the box in each section that most accurately depicts their wishes for future care. Although many of the forms used in the USA contain similar information, there are minor changes or variations that are currently in use. In some states, preferences for use of antibiotics are given in a distinct section, while others include antibiotics within the medical interventions section. Interventions including blood transfusions and dialysis treatments are also 
additional interventions included in some forms but not others. Despite minor differences or inclusion of additional interventions, a majority of forms in use contain three core sections (CPR, Medical Interventions, and Medically Administered Fluids and Nutrition). The West Virginia POST contains three sections. Section A informs patient wishes regarding cardiopulmonary resuscitation (CPR). The patient may elect for CPR or Do Not Attempt Resuscitation (DNR). This section is intended to inform treatment only when patient is in cardiopulmonary arrest and refers medical staff to the remaining sections to inform other types of care.

Section B offers options for three different levels of medical interventions the patient can elect to receive. These include: Comfort Measures, Limited Additional Interventions, and Full Interventions.

Comfort Measures focus on patient comfort and symptom management. Comfort Measures allows for use of medications and treatments such as wound care to relieve pain and suffering. Comfort Measures restricts patient medical transfer from their current location of care to situations only when comfort needs cannot be met in the current location.

Limited Additional Interventions include the same level of care as described above but allows for additional basic medical treatments beyond symptom management. The use of intubation or mechanical ventilation, however, is restricted under Limited Interventions. Patient transfers are permitted if medically indicated but patient admission to intensive care units are avoided.

Patient preference for Full Interventions allows for all medical treatment that is available in Comfort Measures and limited interventions, and additionally permits use of intubation, ventilation, and cardioversion. Hospital transfers are permitted, including treatment in the 
intensive care unit. Full Interventions allow for full access to life-sustaining medical interventions.

Section $\mathrm{C}$ contains choices for medically administered fluids and nutrition. A patient may elect to have no IV fluids, IV fluids for a specified amount of time, or long-term IV fluid use if indicated. The patient also must select preference for the use of feeding tubes. Options include no feeding tube use, feeding tube for a specified trial period, or grant long-term feeding tube use.

Section D lists the parties involved in the discussion (i.e., patient, spouse, surrogate, or medical power of attorney) and signatures of the patient and physician. The West Virginia POST also allows for the patients to submit their completed POST to the online directory and allow access to treating health care providers.

\section{Research on the POLST}

Since creation of the POLST paradigm in the early 1990's, there have been several studies addressing program implementation as well as the outcomes associated with its use in various care settings. Multiple studies have examined the use of the POLST paradigm across the country, with a majority of research being conducted in nursing homes. Studies of licensed nursing homes in Oregon and New York reported that a majority of surveyed facilities are using a version of the POLST paradigm (Bomba \& Orem, 2015; Hickman, Tolle, Brummel-Smith, \& Carley, 2004) including $71 \%$ of nursing homes in Oregon, and 58\% of nursing homes in New York. New York also reports a majority of hospitals, 70\%, currently using the POLST paradigm (Bomba \& Orem, 2015). Studies on POLST implementation in California show staff members in $82 \%$ of nursing homes and $84 \%$ of hospitals had received educational training for completing the POLST (Sugiyama et al., 2013; Wenger et al., 2013). POLST paradigm forms are also being 
used in hospices across various states. Hickman and colleagues (2009) reported POLST paradigm use in $100 \%$ of surveyed hospices in Oregon and $85 \%$ in West Virginia). Use of the POLST paradigm is expected to continually increase as more states establish implementation and training methods. In a sample of nearly 300,000 individuals, Jennings and colleagues (2016) demonstrated a sharp increase in California nursing home residents with a POLST during 2011, increasing from 33 to $49 \%$.

There is considerable support in the literature demonstrating the benefits and positive outcomes associated with patients who complete a POLST. A documented preference for Comfort Measures emphasizes the patient's desire to remain in the current location of care and avoid medical admission. Multiple studies have found that patients who document preferences for Comfort Measures are significantly less likely to die in the hospital and significantly more likely to die in their preferred location (e.g., their own home, nursing residence) (Fromme, Zive, Schmidt, Cook, \& Tolle, 2014; Hammes et al., 2012; Lee et al., 2000; Moss, Zive, Falkenstine, Fromme, \& Tolle, 2016; Tolle, Tilden, Nelson, \& Dunn, 1998). This finding was also supported in a study of out-of-hospital deaths among West Virginia residents. Patients with a completed WV POST were significantly more likely to have an out-of-hospital death when compared to patients with advance directives but no POST (Pedraza, Culp, Falkenstine, \& Moss, 2016). A There is evidence to support consistency between stated treatment preferences and actual care received when the POLST paradigm is employed. A multi-state review of nursing home residents found that documented POLST orders were consistent with treatment received 94\% of the time ( $\mathrm{n}=681$ ) (Hickman et al., 2011). Studies have found that no patient has received 
unwanted CPR that had a documented preference for DNR in the POLST form (Hickman et al., 2009; Tolle, Tilden, Nelson, \& Dunn, 1998).

Another source of support for implementing the POLST paradigm is the benefits for initiating and maintaining communication between providers and patients. For example, $90 \%$ of health care providers in a North Carolina nursing home endorsed the belief that use of the POLST paradigm improves communication between patients and physicians (Caprio, Rollins, \& Roberts, 2012). Other research suggests that staff members believe the POLST paradigm reliably expresses patient treatment preferences (Hickman et al., 2004; Hickman et al., 2009). Seventyone surveyed hospice staff members from Oregon, West Virginia, and Wisconsin, found the POLST paradigm useful in initiating conversations about patient preferences $(96 \%)$, ensuring patient treatment preferences are honored (94\%), and feeling more comfortable knowing what to do when a POLST is available (93\%) (Hickman et al., 2009). In a survey of Emergency Medical Technicians (Schmidt, Hickman, Tolle, \& Brooks, 2004), 75\% of EMT’s believed the POLST paradigm provided clear instructions about patient wishes and $93 \%$ believed it to be useful in determining which treatments to provide during cardiopulmonary arrest.

The POLST paradigm has been shown to be useful in providing treatment options to patients, allowing for a more patient-centered and individualistic treatment plan. In a sample of nursing home residents, living and deceased, residents with a completed POLST form were more likely to have had orders for additional treatments beyond CPR than those without (Hickman et al., 2010). Further, Hickman (2004) showed that $77 \%$ of forms indicating a DNR preference also had preferences for more than the lowest level of care in at least one other form category. These findings contradict the common misconception that a DNR preference means "do not treat." On 
the contrary, when patients are given a choice, many prefer to have a choice for aggressive treatments in certain situations (Hickman et al., 2009).

Despite many benefits of using the POLST paradigm, there are still questions of implementation and dissemination that must be answered. Although POLST programs are guided by the NPPTF requirements, the process of completing a POLST during a medical encounter widely varies across states and clinics. As stated previously, individuals completing a POLST with patients include social workers, nurses, and medical doctors, all of who have different training experiences and areas of expertise. Medical settings also vary on when a POLST form is completed and what information is presented to the patients.

\section{Patient Decision Aids}

The use of decision aids offers an avenue for addressing the lack of standardization in the completion of the POLST and the uncertainty of whether patients are making informed decisions that are consistent with their values. A patient decision aid (PtDA) is an instrument that is intended to help patients make health related decisions by identifying the decision to be made and providing information on treatment choices and likely outcomes (O’Connor et al., 2009). Additionally, patient decision aids allow patients to recognize personal values in relation to associated options, harms, and benefits (Stacey et al., 2014). The primary goal of a decision aid is to improve the decision-making process so that the patient arrives at an informed-decision (Stacey et al., 2014). Decision aids are typically implemented in addition to clinician/practitioner counseling, rather than serve as a replacement for this interaction (Elwyn et al., 2006; O'Connor et al., 1999). Decision aids can be presented in numerous ways and forms, including leaflets, handouts, or digital media (Elwyn et al., 2006). 
The development and use of video decision-support tools for advance care planning has been growing in recent years. Video aids can provide realistic images of medical treatments being performed and provide a more accurate representation of life for individuals with advanced illness than written information or verbal narratives alone (Gillick \& Volandes, 2009). Research has also indicated that patients who viewed a video aid had higher knowledge scores and reduced decisional uncertainty compared to those who only received a verbal narrative (ElJawahri et al., 2010; Volandes et al., 2012). Multiple studies have demonstrated patient comfort in viewing videos related to end of life care (El-Jawahri et al., 2010; Volandes et al., 2012). A meta-analysis by Jain and colleagues (2015) found that the use of video decision aids increases patient knowledge related to advance care planning.

Support for the effectiveness of decisions aids for medical decisions has been established through the measurement of several outcomes. A systematic review of patient decision aids (Stacey et al., 2014) identified knowledge, decisional conflict, and satisfaction with decision as the most common variables used to evaluate the effectiveness of decision aids. These variables are important for facilitating informed decisions on the part of the patient and ensuring that decisions are informed and congruent with patient values.

Decisional Conflict is the perceived uncertainty of an individual in making a final decision (Linder et al., 2011). Factors influencing decisional conflict include: feeling informed of treatment options, being clear of personal values impacting the decision, and receiving necessary support to make a decision. Decision aids have been used to reduce patient decisional conflict by making explicit the decision(s) to be made and providing relevant information about options and likely outcomes (O’Connor, 1994). 
Decision aids often evaluate improvements in patient knowledge related to the medical decision. The importance of measuring patient knowledge is to ensure that the individual understands his or her current medical condition, and can articulate evidence-based probabilities and outcomes associated with each method for treating the condition.

Satisfaction with decision also is an important and commonly used outcome measure for evaluating the effectiveness of a decision aid. Satisfaction with decision is different from satisfaction with treatment outcome, and focuses on the time when a decision has been made but has not yet been implemented (Holmes-Rovner et al., 1996).

A recent systematic review by van Weert and colleagues (2016) found that decision aids have also been effective when used with older adults making health decisions. Review authors found improvements in knowledge, increases in risk perception, and decreases in decision conflict as a result of using decision aids.

There has been exponential growth in development of patient decision aids since 1999 (Stacey et al., 2014). Currently, there are over 650 aids available in the Ottawa Decision Aid Library Inventory ranging from acne treatments to surgical procedures for varicose veins.

\section{Patient factors contributing to decision-making}

The POLST paradigm offers a promising approach to ensuring that the end-of-life decisions are honored, and the use of a decision aid is a potentially promising approach to enhancing the process of shared decision-making in the context of completing a POLST form. However, the factors that contribute to the decisions made through the POLST process remain a mystery for the most part. A growing body of research has focused on understanding how individual differences or patient-specific variables may contribute to medical decision-making. 
Currently, there is some debate about whether all patients desire or are comfortable with taking an active role in decision-making (Flynn \& Smith, 2007). Moreover, some patients may desire differing levels of involvement in the decision-making process based on the type of decision or magnitude of the risks associated. Arora \& Mchorney (2000) found that a considerable portion (69\%) of older adult patients prefer their medical provider to make treatment decisions unilaterally. For example, Moumjid and colleagues (2003) found that increased levels of anxiety or situational avoidance as a result of engaging patients as an active member in the decision-making process. Flynn and Smith (2007) found several factors including gender, health status, and level of education, are associated with patient participation in decisionmaking for health care treatments. Females, individuals taking fewer prescription medications, and individuals with a college degree are more likely to prefer an active role in decision-making.

Another promising individual difference variable is the patient's personality. More specifically, researchers have begun to explore the role of personality traits on the decisionmaking process. Personality traits are associated with types of treatment decisions made (Lattie et al., 2016) and decision-making style (Flynn \& Smith, 2007). Higher levels of neuroticism are associated with lower preferences for palliative care, and higher levels of agreeableness are associated with patient preference for palliative care and opposing life support services (Lattie et al., 2016). Neuroticism is also associated with less participation in decision-making while conscientiousness and openness are more likely to characterize patients who prefer an active role in deliberation (Flynn \& Smith, 2007). Although evidence suggests there may not be a "one-sizefits-all" approach to shared decision-making, research on individual differences may enhance our understanding of factors influencing the medical decision-making process. Moreover, it may aid 
healthcare providers to better understand patient choices, improve service provided, and address the individual's decision-making preferences.

\section{Summary}

Research on the POLST paradigm has provided evidence to support the primary aims of the paradigm. It has been shown to be effective in documenting patient preferences for end-oflife treatments and that these wishes are honored the majority $(>90 \%)$ of the time during care (Hickman et al., 2011). Despite benefits revealed in previous studies, there is a paucity of research investigating the nature, quality, and outcomes of the decision-making process of patients completing a POLST form. No previous research has examined what information is shared with patients regarding their choices or the way in which this information is presented. Additionally, there are no published studies that have examined the extent to which patients understand and weigh the potential risks and benefits of their treatments options.

As previously discussed, individual factors such as personality characteristics and desired role in decision-making have significant influence on patient's choices when making medical decisions (Flynn \& Smith, 2007), including decisions related to end-of-life care (Lattie et al., 2016). There are no published studies, however, that have measured the relation between personality traits and decisions made on the WV POST, or the effects of personality characteristics on patient's levels of decisional conflict or satisfaction with decisions.

Based on previous POLST paradigm research, whether patients are making informed and values-based decisions relating to their end-of-life care is unclear. There is a possibility that patients are making decisions without possessing all necessary information, or are making decisions without weighing all presented options. 
In a recent review of the extant POLST paradigm literature, Hickman and colleagues (2015) summarized future directions for POLST research. Among other directions, the authors recommended that future research focus on the quality of POLST decisions, and more specifically, the development of evidence-based decision-support tools for families and individuals completing a POLST.

\section{Current Study}

The purpose of the proposed study was to develop and evaluate a video decision aid for the Medical Interventions section of the WV POST. A video-based aid was chosen for the current study in order to maximize clinical utility and external validity of the project. As argued by Gillick and Volandes (2009), video decision aids provide a more realistic depiction of medical care compared to verbal narratives or written information, and allow participants to better understand the circumstances of the decision. A video-based aid avoided potential literacy issues in the sample and was able to provide the same amount of information as a text-based aid in a shorter period of time.

The outcomes evaluated were; whether a video decision aid can improve patient knowledge related to treatment decisions, increase patient satisfaction with decision, and reduce patient decisional conflict. In addition, the effect of personality traits on an individual's preferred role in decision-making, decisional conflict, and satisfaction with decision were explored.

The primary aim of the study was to develop and evaluate a video decision-aid for the WV POST. Three questions were addressed to evaluate the decision aid.

Question 1: Will the use of a decision aid increase patient knowledge of treatment alternatives, risks and benefits, and likely outcomes? 
Hypothesis 1: Participant total scores on the knowledge test will significantly increase after using the decision aid. Numerous studies have demonstrated that the use of decision aids significantly increases patient knowledge about information to make a medical decision.

Question 2: Will participant decisional conflict decrease following use of the decision aid?

Hypothesis 2: Participant ratings on the measure of decisional conflict will significantly decrease following use of the aid. Several studies (Collins et al., 2009; Laupacis et al., 2006; Mitchell, Tetroe, \& O’Connor, 2001) have demonstrated significant reductions in patient decisional conflict when using decision aids.

Question 3: Will participant satisfaction increase following the use of the decision aid? Hypothesis 3: Participant satisfaction with treatment decision will significantly increase following the use of the aid. Two previous studies using the SWD (Leighl et al., 2011; Williams et al., 2013) have demonstrated significant increases in satisfaction when using decision aids.

A secondary aim of the study was to examine the relation between personality traits and decision-making variables.

Question 1: What is the relation between personality traits (openness to experience, conscientiousness, extraversion, agreeableness, and neuroticism) and a participant's preferred role in decision-making?

Hypothesis 1: Individuals with higher levels of neuroticism will prefer a more passive role in decision-making and individuals with higher levels of agreeableness, conscientiousness, and openness to experience will prefer a more active role in decision-making. This hypothesis is based on previous research (Flynn \& Smith, 2007), which found significant associations between 
all of the "big five" personality traits (with the exception of extraversion) and preferred role in decision-making.

Two exploratory questions were addressed to further examine the second aim.

Question 1: To what extent do personality traits (openness to experience, conscientiousness, extraversion, agreeableness, and neuroticism) predict participants' decisional conflict?

Question 2: To what extent do personality traits predict participants' satisfaction with decision?

Previous evaluations of decision aids have focused on the aid as a method of reducing decisional conflict and improving patient satisfaction with decision. However, there is no published research that has examined how patient-specific factors, such as personality traits, predict a patients' decisional conflict or satisfaction with decision.

\section{Participants and Sample Size}

\section{Method}

Power analyses using G*Power 3.1.9 (Faul, Erdfelder, Buchner, \& Lang, 2013) were conducted to determine the sample size required for the study. The sample size for an a priori matched-pairs $t$-test was determined for an effect size of $f$ of $0.40, a=.05$, and power $=0.80$. The effect size used in the power analysis was based on previous studies evaluating decision aids (Laupacis et al., 2006; O’Connor et al., 1999). The power analysis indicated that a sample size of 41 participants was sufficient to detect significant differences in the sample.

A separate power analysis was conducted to ensure adequate sample size for a linear multiple regression analysis. The sample size was determined by entering the study design as an 
a priori, linear multiple regression with an effect size of $f$ of $0.30, a=.05$, and power $=0.80$. This effect size was based on previous research (Roberts, Kuncel, Shiner, Caspi, \& Goldberg, 2007). The power analysis indicated that a sample of 49 participants was sufficient to detect associations in the sample.

Study participants were recruited from multiple senior citizens centers in Morgantown, $\mathrm{WV}$, and through online advertisements and public postings for psychological research. The sample consisted of 50 English-speaking, community-dwelling older adults (65 years and older) with no self-reported history of cognitive impairment. Older adults were chosen as the study sample to limit participant age as a potential confound. Older adults are more likely to have chronic illnesses than younger adults (Robert Wood Johnson Foundation, 2010) thus the sample conceivably had a more accurate understanding of limitations caused by disease in later life. Recruitment of participants sought to attain generally equal numbers of male and female participants. Due to potential bias in data collection, participants were excluded from the study if they had a current terminal illness or prognosis of less than one year to live. Exclusion criteria for the study were published on all recruitment materials and assessed for by the researcher prior to gaining informed consent. Recruitment brochures for participants described the purpose of the study as an examination of medical decision-making in older adults. Study participants received $\$ 10$ after participating in the study.

See Table 1 for information on sample age, sex, race/ethnicity, education, occupational status, and health outcomes. Participants included 50 older adults, 33 females and 17 males, who ranged in age from $65-93(M=73.08, S D=7.53)$. The vast majority of participants were Caucasian $(\mathrm{N}=49)$. The sample was highly educated, with a majority of participants having completed a 
post-graduate degree (44\%). Most participants were retired (90\%), with a minority of participants $(8 \%)$ working part-time or volunteering. Many participants indicated that they had at least one chronic health condition (66\%). Fifty percent of the participants rated their physical health status as Very Good (50\%). Few participants had a Do-Not-Resuscitate card $(20 \%)$ or a Physician Order for Medical Treatments (14\%).

\section{Development of Aid}

The content of the decision aid was developed through consultation with a physician board-certified in internal medicine and hospice and palliative medicine. Additionally, medical research and scientific publications were examined for up-to-date information about the benefits and burdens of the medical treatments discussed in the video aid. The aid script was revised based on suggestions from a licensed psychologist to improve readability. A small lay audience $(<10)$ not associated with the development of the script was also consulted to detect any issues related to lack of understanding and amount of information presented. The final aid script had a Flesch Reading Ease score of 59.7 and was written at an $8^{\text {th }}$ grade Flesch-Kincaid reading level. The graduate research assistant was filmed reading the aid script in a research-lab setting. A graphic design student then edited the recording and created on-screen text to highlight key information. The final video was then uploaded on to an electronic tablet to be used by participants in the study.

\section{Measures}

Demographics. The demographic questions assessed a variety of individual characteristics including age, sex, ethnicity, highest education attained, annual income, marital status, chronic illness, previous medical procedures, and existing advance directives. 
Decisional Conflict. The Decisional Conflict Scale (DCS) measures patient uncertainty when making health-related decisions (O'Connor, 1994). The DCS is a 16-item measure containing five subscales: informed, clear values, support, uncertainty, and effective decision. The measure uses a Likert scale consisting of five response categories (Strongly Agree, Agree, Neither Agree Or Disagree, Disagree, Strongly Disagree). Raw scores range from 0-64, with higher scores indicating higher levels of decisional conflict. Initial validation using 909 medical patients demonstrated Cronbach's alpha coefficients ranging from 0.78 to 0.92 (O'Connor, 1995). In a sample of 59 outpatients (mean age $=69$ ) with a life-threatening illness (Song \& Sereika, 2006), the DCS has demonstrated limited construct validity evidence by differentiating groups that received an advance care planning intervention and those that had received usual care. A twosample $t$-test revealed significant differences in total DCS scores between usual care and intervention groups $(\mathrm{t}=3.34, \mathrm{p}<.001)$. Decisional conflict had a significant positive association with post-decision anxiety $(\mathrm{r}=0.47, \mathrm{p}=0.006)$ (Song \& Sereika, 2006).

Satisfaction with Decision. The Satisfaction with Decision Scale (SWD) (Holmes-Rovner et al., 1996) is a 6-item measure of patient satisfaction with a health care decision. The measure uses a 5-point, Likert response scale (1=Strongly Disagree, 2= Disagree, 3=Neither Agree or Disagree, 4=Agree, 5=Strongly Agree). Patient ratings are summed, with higher scores indicating increased satisfaction with decision. Cronbach's alpha was 0.88 using a sample of 252 women making decisions for menopause treatment. The SWD has also demonstrated good internal consistency $($ Cronbach's alpha $=0.85)$ in a sample of depressed primary care patients (Wills $\&$ Holmes-Rovner, 2003). At a 12-month follow up, satisfaction with the decision scores were significantly correlated with decisional certainty $(r=0.27, p<0.05)$. Construct validity for the 
SWD was assessed using bivariate correlations between the SWD and similar measures (DCS, overall health, and satisfaction with clinic and health care provider). SWD scores were correlated with subscales of the DCS including: uncertainty $(r=-0.29, p<.01)$ and effective decision subscale $(r=-0.72, \mathrm{p}<.001)$ (Wills \& Holmes-Rovner, 2003). The SWD also had significant correlations with a measure of satisfaction with primary health care provider in the original study $(\mathrm{r}=0.31, \mathrm{p}<.01)$ and a study using depressed patients $(\mathrm{r}=0.23, \mathrm{p}<.05)($ HolmesRovner et al., 1996; Wills \& Holmes-Rovner, 2003). Correlations between the SWD and additional measures followed test developers hypothesized pattern of relationships and correlations from two separate validation studies found similar associations between the SWD and additional measures (Holmes-Rovner et al., 1996; Wills \& Holmes-Rovner, 2003).

Preferred Role in Decision-Making. The Control Preferences Scale (CPS) (Degner, Sloan, \& Venkatesh, 1997) was developed to assess how individuals with life-threatening illness make medical decisions. The measure is designed to assess one's desired role in medical decisionmaking with one's physician. The control preferences construct was developed based on findings from a qualitative study by Degner and Beaton (1987). The CPS identifies three decision-making types: Active, Collaborative, and Passive. The measure uses five statements presented on handout cards (Cards A-E) that describe different levels of involvement in medical decisionmaking. In clinical settings, the "pick one" approach to implementing the CPS is used, where patients select the card with the statement that falls closest to their preferred role in decisionmaking. Participants who prefer card A or B are categorized as preferring an active role in decision-making. Participants who select card $\mathrm{C}$ prefer a collaborative role, and participants who select cards D or E prefer a passive role in decision-making. The CPS has been used in various 
patient samples including patients with cancer, Hep C, and asthma (Lechner et al., 2016).

Despite common use of the measure in recent research (Fraenkel, 2011; Singh et al., 2010) there is currently little psychometric support for reliability and validity.

Knowledge. An 18-item questionnaire was developed by the investigator to evaluate participant knowledge of treatment options and associated risks and benefits. The test consists of multiplechoice items based on information relevant to treatment options specific to the POST. A physician who specializes in palliative care and end-of-life treatment evaluated the questionnaire to assess the appropriateness and adequacy of the content being assessed (i.e., content validity). A participant's total knowledge score was calculated by summing the number of correct answers. The knowledge questionnaire was pilot tested to assess content of the questionnaire.

Personality Traits. The Mini-IPIP (Donnellan, Oswald, Baird, \& Lucas, 2006) is a 20-item, five factor measure of personality derived from the 50-item International Personality Item Pool (Goldberg, 1999). Factors include: Extraversion, Agreeableness, Conscientiousness, Neuroticism, and Intellect/Imagination Internal consistency estimates for the five factors, using Cronbach's alpha, ranged from $0.65-0.82$ in two validation studies including over 3,000 undergraduate participants (Donnellan, Oswald, Baird, \& Lucas, 2006). Convergent validity for the Mini-IPIP was examined using the Big Five Inventory (BFI) (John, \& Srivastava, 1999). Correlation coefficients between the Mini-IPIP and BFI were 0.81 (Extraversion), 0.49 (Agreeableness), 0.66 (Conscientiousness), 0.80 (Neuroticism), and 0.68 (Intellect/Imagination) (Donnellan, Oswald, Baird, \& Lucas, 2006). Findings from a nationally representative sample of 15,701 young adults supported the Mini-IPIP's five-factor structure and scale reliability (Baldasaro, Shanahan, \& Bauer, 2013). 
Clinical Vignette. A clinical vignette was provided to each participant in the study. The vignette provided hypothetical medical information that the participant used to make treatment decisions for medical interventions. The vignette included a diagnosis of metastatic lung cancer and chronic obstructive pulmonary disease. The vignette stated that the individual is no longer responding to treatments and has a prognosis of less than one year to live. Lung cancer and chronic obstructive pulmonary disease were chosen for inclusion in the clinical vignette due to the common occurrence of these diseases in older adults and the progressive nature of these diseases. All participants in the study were provided with the same clinical vignette to reduce potential variance in the data.

Aid Evaluation. A 9-item questionnaire was developed to assess participants' experiences with the video decision aid. Items were included to assess for patient comfort, perceived usefulness, bias, and general acceptability of the aid. Items were modeled from similar evaluation questionnaires used in other video-based decision aid studies (e.g. El-Jawahri et al., 2010; Volandes et al., 2012) as well as from evaluation criteria for decision aids set forth by the International Patient Decision Aid Standards (Elwyn et al., 2006). Items were rated using a 5point, Likert scale $(1=$ Strongly Disagree, $2=$ Disagree, $3=$ Neither Agree or Disagree, 4=Agree, 5=Strongly Agree).

\section{Procedures}

Participants were guided through the study procedures by the graduate student investigator and a team of psychology undergraduate students at WVU. Each of the five students received required trainings for human subjects' research prior to interacting with participants. Trainings included: conflict of interest, responsible conduct of research, and HIPAA. 
Undergraduate research assistants were supervised by the graduate research assistant to ensure the study protocol was followed.

After providing informed consent, participants completed a demographic questionnaire. Next, the participants completed the 20-item Mini-IPIP (personality inventory) and the Control Preferences Scale (preferred role in decision-making).

Participants were then given a hypothetical clinical vignette that provided information necessary to complete the Medical Interventions section of the WV POST. The vignette stated that the participant has end-stage cancer and is no longer responding to chemotherapy or other treatments.

The researcher then presented the participant with a copy of the WV POST informational leaflet. The researcher assessed understanding by asking the participant if the information presented was clear and allowed time for the participant to ask questions to clarify any problems in understanding. Participants were then presented with the 16-item DCS and asked to select a treatment option and complete the measure to provide pre-intervention ratings of decisional conflict for section B of the POST. Next, participants completed the pre-test SWD scale and Knowledge Questionnaire.

Participants were then provided a tablet to view the 7-minute video detailing the three medical interventions options. After viewing the video, participants selected their choice for medical interventions by selecting a treatment option and completing the post-test DCS. Participants then completed post-test SWD scale and Knowledge Questionnaire. Finally, participants completed a 9-item questionnaire to assess the utility and acceptability of the aid. 


\section{Results}

\section{Normality and Missing Data}

Prior to statistical analyses, data were examined for missingness. Data from self-report inventories were included in the final analyses if a response was made for every item. Inventories for dependent measures (personality, decisional conflict, and decisional satisfaction) were excluded if any item was endorsed with two responses or if the inventory had items that were left blank. Mini-IPIP data of five participants, and DCS ratings by three participants were excluded due to missing or double-checked items. Two participants did not complete the CPS measure, and were not included in secondary aim analysis or descriptive data.

Data were examined to determine violations in normality, skew, kurtosis, homoscedasticity and multicollinearity. Skew statistics obtained during descriptive statistics in SPSS revealed no violations of normality, however, a kurtosis value of 4.55 was obtained for extraversion by dividing the kurtosis statistic by the standard error. The kurtosis value was greater than the 1.96 threshold suggested by Field (2013) and indicated a heavy-tailed distribution. The extraversion variable was log-transformed and entered into the regression model. The transformation had no significant effect on results obtained, thus final analyses included the original extraversion variable. There were no violations of homoscedasticity based on visual examination of normal probability plots. Correlations between predictor variables, Variance Inflation Factor, and tolerance statistics for the regression models indicated no multicollinearity.

Data analyses were conducted in Statistical Package for the Social Sciences (version 24). An alpha level of 0.05 was used for the following analyses and results. 


\section{Descriptive Statistics}

The primary outcome variables of the study were knowledge, decisional conflict, and satisfaction with decision. All three primary outcome variables were measured pre- and postintervention. Secondary outcome variables included preferred decision-making style and personality traits. Please see Table 1 for the demographic characteristics of the participants. See Table 2 for the means, standard deviations, and bivariate correlations for all study variables.

For preferred role in decision-making participants were grouped to one of three categories: active, collaborative, or passive decision-making styles. Nineteen participants were categorized as active, 24 as collaborative, and 5 as passive.

See Table 3 for complete descriptive statistics and $t$-test results for Aim 1.

\section{Aim 1 Hypothesis 1}

Hypothesis 1: Participant total scores on the knowledge test will significantly increase after using the decision aid.

The results of a paired-samples $t$-test analysis revealed a significant increase in participant total knowledge scores from pre-intervention $(M=11.24, S D=2.77)$ to postintervention $(M=14.32, S D=2.89)$. The mean difference, $3.08,95 \% \mathrm{CI}[-3.67,-2.49]$ was significant $t(49)=-10.43, p<.001$, and represented a large-sized effect, $d=-1.09$.

\section{Aim 1 Hypothesis 2}

Hypothesis 2: Participant ratings of decisional conflict will significantly decrease following use of the decision aid.

A paired-samples $t$-test analysis revealed significant decreases in participant decisional conflict from pre-intervention $(M=12.00, S D=9.42)$ to post-intervention $(M=8.15, S D=$ 
9.13). The mean difference, $3.85,95 \%$ CI $[2.00,5.70]$ was significant $t(49)=4.20, p=.001$ and represented a medium-sized effect, $d=0.42$.

\section{Aim 1 Hypothesis 3}

Hypothesis 3: Participant scores on decisional satisfaction will significantly increase following use of the aid.

The results of a paired-samples $t$-test analysis revealed significant increases in participant decisional satisfaction pre-intervention $(M=10.14, S D=3.73)$ to post-intervention $(M=8.70$, $S D=3.00)$. The mean difference, $1.44,95 \%$ CI $[0.62,2.26]$ was significant $t(49)=3.55, p=$ .001 , represented a medium-sized effect, $d=0.43$. Decisional satisfaction items were coded such that lower values represented higher satisfaction.

\section{Aim 2 Hypothesis 1}

Hypothesis 1: Neuroticism will predict a passive role in decision-making, and agreeableness, conscientiousness, and openness to experience will predict an active role in decision-making.

A multinomial logistic regression analysis was conducted to examine the relation between personality traits and preferred role in decision-making. Extraversion, agreeableness, conscientiousness, neuroticism, and imagination were used as predictor variables for determining group membership for desired decision-making role (active, collaborative, passive). The passive decision-making group was used as the reference group. The overall regression model was significant, $\chi^{2}=19.29, p<.05$. Pseudo R-Square values indicated that $23 \%$ to $42 \%$ of the variability in decision-making style was accounted for by personality traits included in the model. Although the overall model was significant, the classification accuracy rate was 55.8\%, 
indicating that the model was only slightly more accurate than chance alone. Likelihood ratio tests revealed that extraversion $\left(\chi^{2}=4.55, p=.029\right)$, agreeableness $\left(\chi^{2}=10.75, p=.005\right)$, and neuroticism $\left(\chi^{2}=19.99, p=.004\right)$, were all significant traits related to the prediction of decisionmaking style. However, parameter estimates revealed neuroticism was the only trait that was significantly associated with a particular decision-making style (collaborative), $b=1.28$, Wald $\chi^{2}$ $=3.92, p=.048$. Participants were more likely to prefer a collaborative style compared to a passive style if they had higher levels of neuroticism. For collaborative decision makers, neuroticism had an Odds Ratio $=3.58(95 \%$ CI 1.02 to 12.65$)$. The analysis was repeated using active decision-makers as the reference group, however no other personality traits significantly predicted group membership in decision-making styles. See Table 4 for regression coefficients and Odds Ratio statistics.

\section{Exploratory Question 1: To what extent are personality traits (openness to experience,} conscientiousness, extraversion, agreeableness, and neuroticism) associated with participant $\underline{\text { decisional conflict? }}$

Multiple linear regression analyses were performed to examine the relation between personality traits and decisional conflict at both pre- and post-intervention. Personality traits were entered as predictor variables in regression equations to explain the relation with decisional conflict. Analyses failed to find significant relations between personality traits and preintervention ratings of decisional conflict, $F(5,37)=1.94, p=.11 ; R^{2}=.208$, or post-intervention decisional conflict $, F(5,37)=2.29, p=.06 ; R^{2}=.236$. No personality trait was a significant predictor of decisional conflict. Please refer to Table 5 for more detail. 
Exploratory Question 2: To what extent are personality traits related to participants' $\underline{\text { satisfaction with decision? }}$

Multiple linear regression analyses were performed to examine the relation between personality traits and participant satisfaction with decision. Personality traits were entered as predictor variables in regression equations to explain the relation with decisional satisfaction. Findings from the analyses indicated no relation between personality traits and pre-intervention ratings of satisfaction, $F(5,39)=1.18, p=.34 ; R^{2}=.131$, but a significant relation was found for post-intervention decisional satisfaction ratings $F(5,39)=2.59, p<.05 ; R^{2}=.250$. However, no personality trait was a significant predictor of satisfaction with decision at pre- or post-test. Please refer to Table 5 for regression coefficients of decisional conflict and satisfaction.

Participants' provided positive feedback regarding the perceived usefulness and utility of the aid. Over $90 \%$ of the sample indicated that the aid did not appear to be biased toward a particular decision, that the aid was helpful, that they would recommend the video to a friend or family member, and that they felt comfortable using the video aid.

\section{Discussion}

There is an extensive body of literature supporting the use of decision aids for individuals making healthcare decisions (Stacey et al., 2014). The most common types of decision aids created for use with older adults are intended for medical treatments associated with end-of-life care such as CPR (El-Jawahri et al., 2015; Epstein et al., 2013), feeding tubes (Hanson et al., 2011; Mitchell, Tetroe, \& O’Connor, 2001), and levels of medical intervention (El-Jawarhi 2010; Wilson et al., 2005). However, to date, there have been no published studies examining the use of a decision aid to complete physician orders for medical treatments. The present study 
examined the effects of a decision aid specifically targeting the West Virginia POST form. Further, this study aimed to provide initial support for the utility of the decision aid to improve aspects of decision-making including; uncertainty, knowledge, and satisfaction, as they relate to the medical interventions (Section B) of the POST form. The secondary aim was to investigate the role of personality traits in the prediction of decision-making variables; decisional conflict, satisfaction with decision, and preferred role in decision-making.

\section{Overview of Findings}

This section reviews the results of the present study and is followed by a discussion of the significance of the findings and contribution to the existing literature. The limitations of the study and future directions of research also are discussed.

Evaluation of the decision aid was based on three measures: knowledge, decisional conflict, and decisional satisfaction. Knowledge is the most studied construct when evaluating the effectiveness of a medical decision aid (Stacey et al., 2014). The first hypothesis, that following use of the decision aid, knowledge assessment scores would increase, was supported. The current study found significant differences in number of correct answers when comparing participant knowledge scores before and after the intervention. These findings are consistent with the results of numerous decision aid studies (e.g., El-Jawahri et al., 2015; Epstein et al., 2013; Schroy et al., 2011). El-Jawahri and colleagues (2015) found that a video aid for CPR and intubation significantly improved knowledge scores in a sample of hospitalized older adults. Also, Schroy and others (2011) found post-test increases in patients' knowledge regarding the risks and benefits of colorectal cancer screening. Epstein and colleagues (2013) found that patients with gastrointestinal cancer had significantly more knowledge about the treatment 
decision for CPR and advance care planning after either viewing a video or listening to an audiotape aid. Despite the variation in study design and population samples across these and the present study, significant improvements to knowledge were found. The present findings suggest that participants acquired the necessary information required to make informed decisions.

The hypothesis that decisional conflict would decrease following use of the aid was supported. Consistent with other studies including decisional conflict as an outcome variable, the current study found significant decreases in participant ratings of decisional conflict after viewing the aid (Dale-Collins et al., 2009; El-Jawahri et al., 2010; Mitchell, Tetroe, \& O'Connor, 2001). For example, using the Uncertainty subscale of the DCS, El-Jawahri et al (2010) found the use of a video aid significantly decreased decisional conflict in cancer patients making decisions for CPR and medical interventions. Dale-Collins and colleagues (2009) found that women with early-stage breast cancer reported less decisional conflict regarding a mastectomy or breast-conserving surgery after viewing a video aid. Mitchell et al (2001) demonstrated that an audio-aid describing feeding options for cognitively impaired older adults decreased decisional conflict among surrogate decision-makers. Findings from the present, and these previous studies suggest a generality of effect on decisional conflict when using decision aids across a variety of clinical populations, presenting problems, and even surrogate decision-makers. Significant improvements in participants' ratings of decisional conflict were found despite low levels of decisional conflict at pre-test.

The last hypothesis regarding the effectiveness of the decision aid was that the aid would increase participants' satisfaction with the treatment decision was supported. As was the case with Laupacis et al. (2006), the current study found significant increases in participant's 
decisional satisfaction. The study conducted by Laupacis and colleagues (2006) found that patients making decisions about blood infusion were significantly more satisfied with the decision using subscales of the Decision Satisfaction Inventory (DSI: Barry, Cherkin, Chang, Fowler, \& Skates, 1997). Using a one-item, 5-point Likert scale, Heller and colleagues (2008) found that patients with breast cancer were more satisfied about their decision for mastectomy after using an interactive aid. Using the SWD, Montgomery et al., (2007) found that pregnant women were more satisfied with their decision whether or not to have a caesarean section delivery after using a decision aid. Improvements found in satisfaction with decision in the current study and previous studies, suggest that decision aids have consistent effects on satisfaction despite variation in study populations and satisfaction measures used.

The second aim of the study was to examine the relation between personality traits and participants' preferred role in decision-making, and ratings of decisional conflict and decisional satisfaction. The hypothesis that neuroticism would predict a passive role in decision-making was not supported. Neuroticism, agreeableness, and extraversion were significant predictors in the regression model. However, higher levels of neuroticism significantly predicted a collaborative compared to a passive style. This finding is contrary to a previous study by Flynn and Smith (2007) that found that individuals with higher levels of neuroticism were more likely to prefer a passive role in decision-making. Multiple aspects of the current study may explain the difference between the present results and those of Flynn and Smith. The current sample was predominantly female (66\%) and highly educated with $64 \%$ of participants having completed college or post-graduate degrees. Both female sex and higher education have been found to be significantly associated with an active role in decision-making and desire to be more informed 
regarding medical decisions (Say, Murtagh, \& Thomson, 2006; Singh et al., 2010; Sung, Raker, Myers, \& Clark, 2011). The demographic characteristics of the current study were markedly different from the larger and more nationally representative sample collected by Flynn and Smith $($ Female $=54 \%$, College and Postgrad $=28 \%)$. The effect of these sample characteristics were evident in the current study, given that only five participants preferred a passive role in decisionmaking with the majority preferring collaborative (24) and active (19). Also, the nature of the medical decision is markedly different than in the study by Flynn and Smith. The current study elicited participants' preferences for medical decisions related to end-of-life care, whereas Flynn and Smith did not define a particular medical scenario. The seriousness of the circumstances surrounding the decisions to be made in the current study may have influenced the participants' desire to be more involved in the decision-making process.

Two exploratory questions were included to investigate the potential relation between participant personality traits and levels of decisional conflict and satisfaction with decision. Multiple regression analyses failed to detect significant relations between the five personality traits and pre- and post-intervention scores on decisional conflict. No personality trait included in the model uniquely accounted for change in decisional conflict.

Although no relation was found between pre-test satisfaction and personality traits, an overall significant relation was found between the combination of five personality traits and post-intervention decisional satisfaction, but not for any individual trait. This suggests that none of the individual predictors were sufficiently strong to reach significance, but collectively the predictors account for significance. It is possible that the study was underpowered to detect significant effects on decisional conflict and satisfaction due to excluded data. G*Power analysis 
indicated that 49 participants would be sufficient to detect significant effects, however several participants' personality measures were excluded due to missingness, which resulted in only 45 personality measures being included in regression analyses.

The exploratory questions were not guided by previous research or empirical hypotheses, but rather by the desire to identify variables that could potentially influence the outcome measures. The finding from the exploratory analyses merit brief discussion as they relate to future research and clinical implications. As discussed previously in this manuscript, personality traits have been found to be predictive of both treatment decisions made (Lattie et al., 2016) and preferred decision-making style (Flynn \& Smith, 2007), although no known study has examined the relation between personality traits and decisional outcome variables. The mixed findings in the current study suggest that there may in fact be a relation, although more research is needed to determine the nature and parameters of the relation. The current study, without existing empirical evidence to support hypotheses, may have been underpowered to detect significant effects on decisional conflict and satisfaction.

\section{Limitations}

The current study is not without limitations. Sample demographic characteristics for sex and education were not representative of the older adult general population in the United States. The sample was highly educated, with the largest group having completed post-graduate degrees (44\%). Also, the sample was almost exclusively Caucasian (98\%), although this is comparable to the demographic characteristics of the residents of West Virginia (93.6\%), where the study was conducted (U.S. Census Bureau, 2016). In the present study, patient sex and race may have influenced a variety of variables associated with medical decision-making (e.g., patient 
involvement in decision-making, (Singh et al., 2010); preferences for life-prolonging treatments, (Frost, Cook, Heyland, \& Fowler, 2011); and desire to be well-informed and seek medical information, (Sung et al., 2010). Further, the current study employed a hypothetical clinical vignette to allow participants to make decisions about end-of-life care despite not being terminally ill. It is common for studies of end-of-life decision aids to use hypothetical or future health scenarios to make treatment decisions (Cardona-Morrell et al., 2017). While this approach may enhance the internal validity of the study, hypothetical and future health scenarios may not adequately engage the participant in the decision-making process. Participants may lack the ability to imagine themselves in a health status that significantly differs from their current health status, particularly if they have not had a serious illness in the past. Additionally, participants may not be able to accurately predict their thoughts or feelings about life-prolonging treatments if they have not been exposed to these types of discussion in the past. Another limitation of the study was that most of the primary measures used in the study, with the exception of the DCS, have not been studied for use specifically with older adults. It is recommended to use measures that have been demonstrated validity and reliability evidence with the intended population to ensure that the construct is being appropriately assessed. Lastly, the study did not utilize a control group, which leaves some uncertainty regarding the exact mechanism influencing the results obtained.

\section{Future Directions}

There are several directions for future research. One might build on the initial findings of the current study and develop a decision aid that addresses the entire POST form. A decision aid for the entire POST would also include information for cardiopulmonary resuscitation and 
medically administered fluids and nutrition in addition to levels of medical care that were discussed in the current study.

A second direction for research might be the examination of the effectiveness of a decision aid for POST forms in patient populations with life-limiting illness or individuals who are receiving end-of-life medical care. This approach could avoid the issues previously discussed when using hypothetical or future-based decisions.

Another research direction might be the investigation of the experience and attitudes of medical staff that implement decision aids for end-of-life medical treatments in clinical practice. Topics would include staff acceptability, clinical utility including time and resources required to deliver, and feasibility in various settings. This would allow researchers to identify and address any barriers to use in hospital and outpatient settings. Similarly, another study could examine the comfort level of medical staff using the decision aid in a clinical setting, and determine the extent to which the decision aid was useful in initiating conversations about end-of-life care.

Although decision aids were designed to supplement patient-provider communication, little research has examined the effects of using decision aids on patient-provider outcomes such as communication, trust, and general satisfaction with the medical provider. Thus, one might examine the utility of the decision aid in facilitating shared decision-making, and the influence of using a decision aid on increasing patient-physician trust, communication, and satisfaction with the interaction with the medical provider.

A future research study could explore whether a decision aid for the POST influences the types of treatment decisions made. Finally, a study could investigate the influence of financial 
cost in determining the types of treatment decisions individuals make and whether that cost may contribute to variables such as decisional conflict or satisfaction.

\section{Conclusions and Implications}

The goal of the present study was to develop and evaluate a decision aid for the medical interventions section of the West Virginia POST form. After viewing the aid, participants better understood treatment options and associated risks and benefits pertinent to the medical decision. Participants also reported feeling more informed, more certain, and less conflicted regarding their treatment decision. Lastly, participants reported greater satisfaction with information received, with their decision, and that the decision was more congruent with personal values. Participants with higher levels of neuroticism preferred a collaborative decision-making role compared to a passive role, which is contrary to previous literature. Although personality traits predicted a participant's satisfaction with decision at post-test, there were no traits that uniquely accounted for variance in post-test satisfaction. There were no significant relations between personality traits and pre-test satisfaction or pre- post-test decisional conflict. An overwhelming majority of participants rated the decision aid as useful, unbiased, and a tool that they would recommend to a friend or family member.

The results show that in a non-patient sample, a decision aid can be useful in improving decisional outcomes for individuals making POST medical decisions. The current study provides foundational support for the use of decision aids with POST forms and provides evidence for improving decisional outcomes for individuals completing these forms. This study is important because it found that participants' completing the POST can be taught relevant information for making an informed decision. Second, the study demonstrated that a decision aid, when applied, 
reduces feelings of uncertainty and conflict regarding end-of-life medical care decisions. Third, an aid can serve to increase participant satisfaction of the treatment decision made. Lastly, personality traits can influence a person's preferred role in decision-making, but more research is required to investigate the relation between personality and decisional outcomes. 


\section{References}

Anderson, G. F. (2010). Chronic care: making the case for ongoing care. Robert Wood Johnson Foundation.

Arora, N. K., \& Mchorney, C. A. (2000). Patient Preferences for Medical Decision Making: Who Really Wants to Participate? Source: Medical Care, 38(3), 335-341. http://doi.org/http://dx.doi.org/10.1097/00005650-200003000-00010

Baldasaro, R. E., Shanahan, M. J., \& Bauer, D. J. (2013). Psychometric Properties of the MiniIPIP in a Large, Nationally Representative Sample of Young Adults. Journal of Personality Assessment, 95(1), 74-84. http://doi.org/10.1080/00223891.2012.700466

Barry, M. J., Cherkin, D. C., YuChiao, C., Fowler, F. J., \& Skates, S. (1997). A randomized trial of a multimedia shared decision-making program for men facing a treatment decision for benign prostatic hyperplasia. Disease Management and Clinical Outcomes, 1, 5-14. http://doi.org/10.1016/S1088-3371(96)00004-6

Bomba, P. A., Morrissey, M. B., \& Leven, D. C. (2011). Key role of social work in effective communication and conflict resolution process: Medical Orders for Life-Sustaining Treatment (MOLST) Program in New York and shared medical decision making at the end of life. Journal of Social Work in End Life Palliative Care, 7(1), 56-82. Journal Article. http://doi.org/10.1080/15524256.2011.548047

Bomba, P. A., \& Orem, K. (2015). Lessons learned from New York's community approach to advance care planning and MOLAT. Annals of Palliative Medicine, 4(1), 10-21. Journal Article. http://doi.org/10.3978/j.issn.2224-5820.2015.01.05

Caprio, A. J. (2014). Medical Orders for Scope of Treatment (MOST): honoring patient 
preferences across the continuum of care. North Carolina Medical Journal, 75(5), 349-350. Journal Article. Retrieved from http://www.ncbi.nlm.nih.gov/pubmed/25237880

Caprio, A. J., Rollins, V. P., \& Roberts, E. (2012). Health care professionals' perceptions and use of the medical orders for scope of treatment (MOST) form in North Carolina nursing homes. Journal of the American Medical Directors Association, 13(2), 162-168. http://doi.org/10.1016/j.jamda.2010.07.006

Collins, E. D., Moore, C. P., Clay, K. F., Kearing, S. A., O’Connor, A. M., Llewellyn-Thomas, H. A., ... Sepucha, K. R. (2009). Can women with early-stage breast cancer make an informed decision for mastectomy? Journal of Clinical Oncology, 27(4), 519-525. http://doi.org/10.1200/JCO.2008.16.6215

Degner, L. F., Sloan, J. A., \& Venkatesh, P. (1997). The Control Preferences Scale. Canadian Journal of Nursing Research, 29(3), 21-43.

Donnellan, M. B., Oswald, F. L., Baird, B. M., \& Lucas, R. E. (2006). The mini-IPIP scales: tiny-yet-effective measures of the Big Five factors of personality. Psychological Assessment, 18(2), 192-203. http://doi.org/10.1037/1040-3590.18.2.192

El-Jawahri, A., Mitchell, S. L., Paasche-Orlow, M. K., Temel, J. S., Jackson, V. A., Rutledge, R. R., ... Volandes, A. E. (2015). A Randomized Controlled Trial of a CPR and Intubation Video Decision Support Tool for Hospitalized Patients. Journal of General Internal Medicine, 30(8), 1071-1080. http://doi.org/10.1007/s11606-015-3200-2

El-Jawahri, A., Podgurski, L. M., Eichler, A. F., Plotkin, S. R., Temel, J. S., Mitchell, S. L., ... Volandes, A. E. (2010). Use of video to facilitate end-of-life discussions with patients with cancer: A randomized controlled trial. Journal of Clinical Oncology, 28(2), 305-310. 
http://doi.org/10.1200/JCO.2009.24.7502

Elwyn, G., O’Connor, A., Stacey, D., Volk, R., Edwards, A., Coulter, A., ... Collaboration, I. P. D. A. S. (IPDAS). (2006). Developing a quality criteria framework for patient decision aids: online international Delphi consensus process. British Medical Journal, 333(7565), 417. http://doi.org/10.1136/bmj.38926.629329.AE

Epstein, A. S., Volandes, A. E., Chen, L. Y., Gary, K. a, Li, Y., Agre, P., ... O’Reilly, E. M. (2013). A randomized controlled trial of a cardiopulmonary resuscitation video in advance care planning for progressive pancreas and hepatobiliary cancer patients. Journal of Palliative Medicine, 16(6), 623-31. http://doi.org/10.1089/jpm.2012.0524

Flynn, K. E., \& Smith, M. a. (2007). Personality and health care decision-making style. Journal of Gerontology, 62(5), P261-P267. http://doi.org/62/5/P261

Fraenkel, L. (2011). Uncertainty and patients' preferred role in decision making. Patient Education and Counseling, 82(1), 130-132. http://doi.org/10.1016/j.pec.2010.02.026

Fromme, E. K., Zive, D., Schmidt, T. A., Cook, J. N., \& Tolle, S. W. (2014). Association between Physician Orders for Life-Sustaining Treatment for Scope of Treatment and inhospital death in Oregon. Journal of the American Geriatric Society, 62(7), 1246-1251. http://doi.org/10.1111/jgs.12889

Fromme, E. K., Zive, D., Schmidt, T. A., Olszewski, E., \& Tolle, S. W. (2012). POLST Registry do-not-resuscitate orders and other patient treatment preferences. Journal of the American Medical Association, 307(1), 34-35. http://doi.org/10.1001/jama.2011.1956

Goldberg, L. R. (1999). The IPIP-NEO (International Personality Item Pool Representation of the NEO PI-R ${ }^{\mathrm{TM}}$ ). Personality Psychology in Europe, 7, 7-28. 
Hammes, B. J., Rooney, B. L., Gundrum, J. D., Hickman, S. E., \& Hager, N. (2012). The POLST program: a retrospective review of the demographics of use and outcomes in one community where advance directives are prevalent. Journal of Palliative Medicine, 15(1), 77-85. http://doi.org/10.1089/jpm.2011.0178

Hanson, L. C., Carey, T. S., Caprio, A. J., Lee, T. J., Ersek, M., Garrett, J., ... Mitchell, S. L. (2011). Improving decision-making for feeding options in advanced dementia: A randomized, controlled trial. Journal of the American Geriatrics Society, 59(11), 20092016. http://doi.org/10.1111/j.1532-5415.2011.03629.x

Heller, L., Parker, P. a, Youssef, A., \& Miller, M. J. (2008). Interactive digital education aid in breast reconstruction. Plastic and Reconstructive Surgery, 122(3), 717-24. http://doi.org/10.1097/PRS.0b013e318180ed06

Hickman, S. E., Keevern, E., \& Hammes, B. J. (2015). Use of the physician orders for lifesustaining treatment program in the clinical setting: A systematic review of the literature. Journal of the American Geriatrics Society, 63(2), 341-350. http://doi.org/10.1111/jgs.13248

Hickman, S. E., Nelson, C. A., Moss, A. H., Hammes, B. J., Terwilliger, A., Jackson, A., \& Tolle, S. W. (2009). Use of the Physician Orders for Life-Sustaining Treatment (POLST) paradigm program in the hospice setting. Journal of Palliative Medicine, 12(2), 133-41. http://doi.org/10.1089/jpm.2008.0196

Hickman, S. E., Nelson, C. A., Perrin, N. A., Moss, A. H., Hammes, B. J., \& Tolle, S. W. (2010). A comparison of methods to communicate treatment preferences in nursing facilities: Traditional practices versus the physician orders for life-sustaining treatment program. 
Journal of the American Geriatrics Society, 58(7), 1241-1248.

http://doi.org/10.1111/j.1532-5415.2010.02955.x

Hickman, S. E., Tolle, S. W., Brummel-Smith, K., \& Carley, M. M. (2004). Use of the physician orders for life-sustaining treatment program in Oregon nursing facilities: Beyond resuscitation status. Journal of the American Geriatrics Society. http://doi.org/10.1111/j.1532-5415.2004.52402.x

Holmes-Rovner, M., Kroll, J., Schmitt, N., Rovner, D. R., Breer, M. L., Rothert, M. L., ... Talarczyk, G. (1996). Patient Satisfaction with Health Care Decisions: The Satisfaction with Decision Scale. Medical Decision Making, 16(1), 58-64. http://doi.org/10.1177/0272989X9601600114

Jain, A., Corriveau, S., Quinn, K., Gardhouse, A., Vegas, D. B., \& You, J. J. (2015). Video decision aids to assist with advance care planning: a systematic review and meta-analysis. British Medical Journal Open, 5(6), e007491. http://doi.org/10.1136/bmjopen-2014-007491

Jennings, L. A., Zingmond, D., Louie, R., Tseng, C. H., Thomas, J., O’Malley, K., \& Wenger, N. S. (2016). Use of the Physician Orders for Life-Sustaining Treatment among California Nursing Home Residents. Journal of General Internal Medicine. http://doi.org/10.1007/s11606-016-3728-9

John, O. P., \& Srivastava, S. (1999). Big Five Inventory (Bfi). Handbook of Personality: Theory and Research, 2, 102-138. http://doi.org/10.1525/fq.1998.51.4.04a00260

Lantz, P. M., Janz, N. K., Fagerlin, A., Schwartz, K., Liu, L., Lakhani, I., ... Katz, S. J. (2005). Satisfaction with surgery outcomes and the decision process in a population-based sample of women with breast cancer. Health Services Research, 40(3), 745-767. 
http://doi.org/10.1111/j.1475-6773.2005.00383.x

Lattie, E. G., Asvat, Y., Shivpuri, S., Gerhart, J., O’Mahony, S., Duberstein, P., \& Hoerger, M. (2016). Associations Between Personality and End-of-Life Care Preferences Among Men With Prostate Cancer: A Clustering Approach. Journal of Pain and Symptom Management, 51(1), 52-59. http://doi.org/10.1016/j.jpainsymman.2015.08.005

Laupacis, A., O’Connor, A. M., Drake, E. R., Rubens, F. D., Robblee, J. A., Grant, F. C., \& Wells, P. S. (2006). A decision aid for autologous pre-donation in cardiac surgery -- a randomized trial. Patient Education \& Counseling, 61(3), 458-466. Retrieved from http://ezproxy.library.yorku.ca/login?url=http://search.ebscohost.com/login.aspx?direct=tru $\mathrm{e} \& \mathrm{db}=\mathrm{rzh} \& \mathrm{AN}=2009212053 \&$ site $=$ ehost-live

Lee, M. A., Brummel-smith, K., Meyer, J., Drew, N., London, M. R., \& A, M. (2000). Outcomes in a PACE Program. Journal of the American Geriatrics Society, 48, 1219-1225.

Leighl, N. B., Shepherd, H. L., Butow, P. N., Clarke, S. J., McJannett, M., Beale, P. J., ... Tattersall, M. H. N. (2011). Supporting treatment decision making in advanced cancer: A randomized trial of a decision aid for patients with advanced colorectal cancer considering chemotherapy. Journal of Clinical Oncology, 29(15), 2077-2084. http://doi.org/10.1200/JCO.2010.32.0754

Linder, S. K., Swank, P. R., Vernon, S. W., Mullen, P. D., Morgan, R. O., \& Volk, R. J. (2011). Validity of a low literacy version of the Decisional Conflict Scale. Patient Education and Counseling, 85(3), 521-524. http://doi.org/10.1016/j.pec.2010.12.012

Matlock, D. D., Keech, T. A. E., Mckenzie, M. B., Bronsert, M. R., Nowels, C. T., \& Kutner, J. S. (2014). Feasibility and acceptability of a decision aid designed for people facing 
advanced or terminal illness: A pilot randomized trial. Health Expectations, 17(1), 49-59. http://doi.org/10.1111/j.1369-7625.2011.00732.x

Mitchell, S. L., Tetroe, J., \& O’Connor, A. M. (2001). A decision aid for long-term tube feeding in cognitively impaired older persons. Journal of the American Geriatrics Society, 49(3), 313-6. http://doi.org/10.1046/j.1532-5415.2001.4930313.x

Montgomery, A. A., Emmett, C. L., Fahey, T., Jones, C., Ricketts, I., Patel, R. R., .. Murphy, D. J. (2007). Two decision aids for mode of delivery among women with previous caesarean section: randomised controlled trial. British Medical Journal. http://doi.org/10.1136/bmj.39217.671019.55

Moumjid, N., Carrère, M. O., Charavel, M., \& Brémond, A. (2003). Clinical issues in shared decision-making applied to breast cancer. In Health Expectations (Vol. 6, pp. 222-227). http://doi.org/10.1046/j.1369-6513.2003.00241.x

O’Connor, A. M., Bennett, C. L., Stacey, D., Barry, M., Col, N. F., Eden, K. B., ... Rovner, D. (2009). Decision aids for people facing health treatment or screening decisions. Cochrane Database of Systematic Reviews. http://doi.org/10.1002/14651858.CD001431.pub2

O’Connor, A. M., Wells, G. A., Tugwell, P., Laupacis, A., Elmslie, T., \& Drake, E. (1999). The effects of an "explicit” values clarification exercise in a woman's decision aid regarding postmenopausal hormone therapy. Health Expectations, 2(1), 21-32. http://doi.org/10.1046/j.1369-6513.1999.00027.x

O’Connor, a M. (1994). Validation of a decisional conflict scale. Medical Decision Making : An International Journal of the Society for Medical Decision Making, 15(1), 25-30. http://doi.org/10.1177/0272989X9501500105 
O’Connor, a M., Fiset, V., DeGrasse, C., Graham, I. D., Evans, W., Stacey, D., ... Tugwell, P. (1999). Decision aids for patients considering options affecting cancer outcomes: evidence of efficacy and policy implications. Journal of the National Cancer Institute. Monographs, 9(25), 67-80. Retrieved from http://www.ncbi.nlm.nih.gov/pubmed/10854460

Pedraza, S. L., Culp, S., Falkenstine, E. C., \& Moss, A. H. (2016). POST Forms More Than Advance Directives Associated With Out-of-Hospital Death: Insights From a State Registry. Journal of Pain and Symptom Management, 51(2), 240-246. http://doi.org/10.1016/j.jpainsymman.2015.10.003

Pope, T. M., \& Hexum, M. (2012). Legal briefing: POLST: physician orders for life-sustaining treatment. J Clin Ethics, 23(4), 353-376. Retrieved from http://www.ncbi.nlm.nih.gov/pubmed/23469698

Roberts, B. W., Kuncel, N. R., Shiner, R., Caspi, A., \& Goldberg, L. R. (2007). The Power of Personality: The Comparative Validity of Personality Traits, Socioeconomic Status, and Cognitive Ability for Predicting Important Life Outcomes. Perspectives on Psychological Science: A Journal of the Association for Psychological Science, 2(4), 313-45. http://doi.org/10.1111/j.1745-6916.2007.00047.x

Say, R., Murtagh, M., \& Thomson, R. (2006). Patients' preference for involvement in medical decision making: A narrative review. Patient Education and Counseling, 60(2), 102-114. http://doi.org/10.1016/j.pec.2005.02.003

Schmidt, T. A., Hickman, S. E., Tolle, S. W., \& Brooks, H. S. (2004). The Physician Orders for Life-Sustaining Treatment program: Oregon emergency medical technicians’ practical experiences and attitudes. Journal of the American Geriatrics Society, 52(9), 1430-1434. 
http://doi.org/10.1111/j.1532-5415.2004.52403.x

Schroy, P. C. P., Emmons, K., Peters, E., Glick, J. J. T., Robinson, P. A., Lydotes, M. A., ... Heeren, T. T. C. (2011). The impact of a novel computer-based decision aid on shared decision making for colorectal cancer screening: a randomized trial. Medical Decision Making : An International Journal of the Society for Medical Decision Making, 31(1), 93107. http://doi.org/10.1177/0272989X10369007

Sepucha, K. R., Borkhoff, C. M., Lally, J., Levin, C. A., Matlock, D. D., Ng, C. J., ... Thomson, R. (2013). Establishing the effectiveness of patient decision aids: key constructs and measurement instruments. BMC Medical Informatics and Decision Making, 13 Suppl 2, S12. http://doi.org/10.1186/1472-6947-13-S2-S12

Singh, J. A., Sloan, J. A., Atherton, P. J., Smith, T., Hack, T. F., Huschka, M. M., ... Degner, L. F. (2010). Preferred roles in treatment decision making among patients with cancer: a pooled analysis of studies using the Control Preferences Scale. The American Journal of Managed Care, 16(9), 688-96. http://doi.org/10.1016/j.bbi.2008.05.010

Song, M. K., \& Sereika, S. M. (2006). An evaluation of the Decisional Conflict Scale for measuring the quality of end-of-life decision making. Patient Education and Counseling, 61(3), 397-404. http://doi.org/10.1016/j.pec.2005.05.003

Stacey, D., Légaré, F., Nf, C., Cl, B., Mj, B., Kb, E., ... Holmes-rovner, M. (2014). Decision aids for people facing health treatment or screening decisions ( Review ) Decision aids for people facing health treatment or screening decisions. The Cochrane Database of Systematic Reviews. http://doi.org/10.1002/14651858.CD001431.pub4.Copyright Stacey, D., Légaré, F., Lewis, K., Barry, M. J., Bennett, C. L., Eden, K. B., ... Trevena, L. 
(2017). Decision aids for people facing health treatment or screening decisions. Cochrane Database of Systematic Reviews. http://doi.org/10.1002/14651858.CD001431.pub5

Sugiyama, T., Zingmond, D., Lorenz, K. A., Diamant, A., O’Malley, K., Citko, J., ... Wenger, N. S. (2013). Implementing physician orders for life-sustaining treatment in California hospitals: factors associated with adoption. Journal of the American Geriatric Society, 61(8), 1337-1344. http://doi.org/10.1111/jgs.12367

Tolle, S. W., Tilden, V. P., Nelson, C. A., \& Dunn, P. M. (1998). A prospective study of the efficacy of the physician order form for life-sustaining treatment. Journal of the American Geriatric Society, 46(9), 1097-1102. Retrieved from http://www.ncbi.nlm.nih.gov/pubmed/9736102

Vo, H., Pekmezaris, R., Guzik, H., Nouryan, C., Patel, C., Vij, B., ... Wolf-Klein, G. (2011). Knowledge and attitudes of health care workers regarding MOLST (Medical Orders for Life-Sustaining Treatment) implementation in long-term care facilities. Geriatric Nursing, 32(1), 58-62. http://doi.org/10.1016/j.gerinurse.2010.11.002

Volandes, A. E., Brandeis, G. H., Davis, A. D., Paasche-Orlow, M. K., Gillick, M. R., Chang, Y., ... Mitchell, S. L. (2012). A randomized controlled trial of a goals-of-care video for elderly patients admitted to skilled nursing facilities. Journal of Palliative Medicine, 15(7), 805-11. http://doi.org/10.1089/jpm.2011.0505

Volandes, A. E., Paasche-Orlow, M. K., Mitchell, S. L., El-Jawahri, A., Davis, A. D., Barry, M. J., ... Temel, J. S. (2013). Randomized controlled trial of a video decision support tool for cardiopulmonary resuscitation decision making in advanced cancer. Journal of Clinical Oncology, 31(3), 380-386. http://doi.org/10.1200/JCO.2012.43.9570 
Weert, J. C. M. Van, Munster, B. C. Van, Sanders, R., Spijker, R., Hooft, L., \& Jansen, J. (2016). Decision aids to help older people make health decisions : a systematic review and metaanalysis. BMC Medical Informatics and Decision Making. http://doi.org/10.1186/s12911016-0281-8

Wenger, N. S., Citko, J., O’Malley, K., Diamant, A., Lorenz, K., Gonzalez, V., \& Tarn, D. M. (2013). Implementation of physician orders for life sustaining treatment in nursing homes in california: Evaluation of a novel statewide dissemination mechanism. Journal of General Internal Medicine, 28(1), 51-57. http://doi.org/10.1007/s11606-012-2178-2

Williams, R. M., Davis, K. M., Luta, G., Edmond, S. N., Dorfman, C. S., Schwartz, M. D., ... Taylor, K. L. (2013). Fostering informed decisions: A randomized controlled trial assessing the impact of a decision aid among men registered to undergo mass screening for prostate cancer. Patient Education and Counseling, 91(3), 329-336. http://doi.org/10.1016/j.pec.2012.12.013

Wills, C. E., \& Holmes-Rovner, M. (2003). Preliminary validation of the Satisfaction With Decision scale with depressed primary care patients. Health Expectations, 6(2), 149-159. http://doi.org/10.1046/j.1369-6513.2003.00220.x

Wilson, K. G., Aaron, S. D., Vandemheen, K. L., Hebert, P. C., McKim, D. A., Fiset, V., ... O’Connor, A. M. (2005). Evaluation of a decision aid for making choices about intubation and mechanical ventilation in chronic obstructive pulmonary disease. Patient Education and Counseling, 57(1), 88-95. http://doi.org/10.1016/j.pec.2004.04.004 
Table 1

Demographic Information $(n=50)$

\begin{tabular}{|c|c|c|}
\hline Variable & $\mathrm{N}$ & $\%$ \\
\hline \multicolumn{3}{|l|}{ Gender } \\
\hline Male & 17 & 34 \\
\hline Female & 33 & 66 \\
\hline \multicolumn{3}{|l|}{ Race } \\
\hline White & 49 & 98 \\
\hline African-American & 1 & 2 \\
\hline \multicolumn{3}{|l|}{ Marital status } \\
\hline Single & 3 & 6 \\
\hline Married & 19 & 38 \\
\hline Live-in partner & 4 & 8 \\
\hline Divorced & 7 & 14 \\
\hline Widowed & 17 & 34 \\
\hline \multicolumn{3}{|l|}{ Education } \\
\hline GED/High school & 11 & 22 \\
\hline Some college & 7 & 14 \\
\hline College & 10 & 20 \\
\hline Postgraduate & 22 & 44 \\
\hline \multicolumn{3}{|l|}{ Occupation status } \\
\hline Working part-time & 4 & 8 \\
\hline Retired & 45 & 90 \\
\hline Other & 1 & 2 \\
\hline \multicolumn{3}{|l|}{ Chronic illness } \\
\hline Yes & 33 & 66 \\
\hline No & 17 & 34 \\
\hline \multicolumn{3}{|l|}{ Life-threatening procedure } \\
\hline Yes & 20 & 40 \\
\hline No & 30 & 60 \\
\hline \multicolumn{3}{|l|}{ Advance directive } \\
\hline Living will & 3 & 6 \\
\hline MPOA & 4 & 8 \\
\hline Combined Will \& MPOA & 33 & 66 \\
\hline \multicolumn{3}{|l|}{ Medical order } \\
\hline DNR card & 10 & 20 \\
\hline POST & 7 & 14 \\
\hline \multicolumn{3}{|l|}{ Physical Health } \\
\hline Excellent & 4 & 8 \\
\hline Very good & 25 & 50 \\
\hline Good & 18 & 36 \\
\hline Fair & 3 & 6 \\
\hline
\end{tabular}


Table 2

Bivariate Correlations between all Study Variables $(n=50)$

\begin{tabular}{|c|c|c|c|c|c|c|c|c|c|c|c|c|c|}
\hline Variables & $M(S D)$ & 1 & 2 & 3 & 4 & 5 & 6 & 7 & 8 & 9 & 10 & 11 & 12 \\
\hline 1. Pre-test knowledge & $11.24(2.77)$ & & & & & & & & & & & & \\
\hline 2. Pre-test conflict & $12.00(9.42)$ & -.08 & & & & & & & & & & & \\
\hline 3. Pre-test satisfaction & $10.14(3.73)$ & -.03 & $.81 * *$ & & & & & & & & & & \\
\hline 4. Post-test knowledge & $14.32(2.89)$ & $.73 * *$ & .03 & .06 & & & & & & & & & \\
\hline 5. Post-test conflict & $8.15(9.13)$ & .01 & $.77 * *$ & $.67 * *$ & .14 & & & & & & & & \\
\hline 6. Post-test satisfaction & $8.70(3.00)$ & -.03 & $.73 * *$ & $.65 * *$ & .07 & $.94 * *$ & & & & & & & \\
\hline 7. Extraversion & $11.10(2.58)$ & .10 & .25 & $.38 *$ & .19 & .20 & .22 & & & & & & \\
\hline 8. Agreeableness & $8.22(2.27)$ & -.06 & .28 & .26 & -.25 & .28 & $.30 *$ & $.30 *$ & & & & & \\
\hline 9. Conscientiousness & $9.7(2.89)$ & .17 & .17 & .15 & .07 & .27 & .26 & .12 & .12 & & & & \\
\hline 10. Neuroticism & $14.89(2.84)$ & -.08 & -.28 & -.17 & .10 & $-.36^{*}$ & $-.35 *$ & -.21 & -.10 & $-.31 *$ & & & \\
\hline 11. Imagination & $10.91(1.84)$ & -.02 & -.10 & .03 & -.12 & -.05 & -.06 & .20 & $.30 *$ & $-.31 *$ & .02 & & \\
\hline 12. Decision-Making style & $1.71(.65)$ & -.14 & .13 & .15 & -.16 & .16 & .20 & -.06 & .24 & .06 & -.17 & .18 & \\
\hline
\end{tabular}

${ }^{*} p<.05, * * p<.01$ 
Table 3

Descriptive Statistics and t-test Results for Knowledge, Conflict, and Satisfaction

\begin{tabular}{lccccccccc}
\hline & \multicolumn{2}{c}{ Pretest } & & \multicolumn{2}{c}{ Posttest } & \multicolumn{5}{c}{$\begin{array}{c}95 \% \text { CI for } \\
\text { Outcome }\end{array}$} & $\mathrm{M}$ & $\mathrm{SD}$ & & $\mathrm{M}$ & $\mathrm{SD}$ & $\mathrm{n}$ & $\begin{array}{c}\text { Mean } \\
\text { Difference }\end{array}$ & $\mathrm{t}$ & $\mathrm{df}$ \\
\hline Knowledge & 11.24 & 2.77 & & 14.32 & 2.89 & 50 & $-3.67,-2.49$ & $-10.43^{* * *}$ & 49 \\
Conflict & 12.00 & 9.42 & & 8.15 & 9.13 & 47 & $2.00,5.70$ & $4.20^{* * *}$ & 46 \\
Satisfaction & 10.14 & 3.73 & & 8.70 & 3.00 & 50 & $0.62,2.26$ & $3.54^{* *}$ & 49 \\
\hline
\end{tabular}

$* \mathrm{p}<.05$.

$* * \mathrm{p}<.01$.

$* * * \mathrm{p}<.001$. 
Table 4

Summary of Multinomial Logistic Regression Analysis for Variables Predicting Preferred

Decision-Making Style ( $n=43)$

\section{Passive}

Predictor

$B \quad S E B \quad O R$

Active

Intercept

$-16.33 \quad 10.82$

Extraversion

$1.29 \quad .86 \quad 3.63$

Agreeableness

$-1.51$

.77

.22

Conscientiousness

$.08 \quad .25 \quad 1.08$

Neuroticism

$\begin{array}{lll}1.24 & .65 \quad 3.45\end{array}$

Intellect

$.04 \quad .65 \quad 1.04$

Collaborative

$\begin{array}{lccc}\text { Intercept } & -19.08 & 10.91 & \\ \text { Extraversion } & 1.26 & .87 & 3.52 \\ \text { Agreeableness } & -1.51 & .77 & .22 \\ \text { Conscientiousness } & .04 & .24 & 1.04 \\ \text { Neuroticism } & 1.28^{*} & .64 & 3.58 \\ \text { Intellect } & .33 & .64 & .60\end{array}$

Note: reference category is Passive $* p<.05$. 
Table 5

Regression Analyses Predicting Decisional Conflict and Decisional Satisfaction

\begin{tabular}{|c|c|c|c|c|c|c|c|c|}
\hline \multirow{3}{*}{ Variable } & \multicolumn{4}{|c|}{ Decisional Conflict } & \multicolumn{4}{|c|}{ Satisfaction } \\
\hline & \multicolumn{2}{|c|}{ Pre-test } & \multicolumn{2}{|c|}{ Post-test } & \multicolumn{2}{|c|}{ Pre-test } & \multicolumn{2}{|c|}{ Post-test } \\
\hline & $B(S E B)$ & $\beta$ & $B(S E B)$ & $\beta$ & $B(S E B)$ & $\beta$ & $B(S E B)$ & $\beta$ \\
\hline Extraversion & $.61(.58)$ & .17 & $.27(.55)$ & .08 & $.27(.24)$ & .18 & $.12(.18)$ & .10 \\
\hline Agreeableness & $1.1(.66)$ & .27 & $1.02(.63)$ & .26 & $.37(.28)$ & .22 & $.39(.20)$ & .28 \\
\hline Conscientiousness & $.35(.52)$ & .11 & $.57(.49)$ & .18 & $.13(.21)$ & .09 & $.19(.16)$ & .18 \\
\hline Neuroticism & $-.60(.53)$ & -.18 & $-.83(.50)$ & -.26 & $-.11(.22)$ & -.08 & $-.27(.16)$ & .17 \\
\hline Intellect & $-1.20(.81)$ & -.23 & $-.83(.77)$ & -.17 & $-.18(.34)$ & -.08 & $-.31(.25)$ & -.25 \\
\hline$R^{2}$ & & .208 & & .236 & & .131 & & $.250 *$ \\
\hline
\end{tabular}

$* \mathrm{p}<.05$ 
Appendix

The following measures included in the Appendix will be utilized in the proposed study:

Demographics Questionnaire, Mini-IPIP, Control Preferences Scale, Clinical Vignette, Decisional Conflict Scale Satisfaction with Decision Scale, Knowledge Questionnaire, Evaluation of Aid Questionnaire. 


\section{Demographics Questionnaire}

This next section will ask you general questions about yourself.

1. What is your age?

2. What is your biological sex?
a. Male
b. Female

3. What is your race or ethnic background? (please choose one):
a. White/Caucasian (not Hispanic)
b. Black/African-American
c. Asian-American
d. Hispanic
e. Native American
f. Pacific Islander
g. Other

4. Please specify if you selected Other as your answer for question \#3.

5. What is your marital status?
a. Single
b. Married
c. Live-in partner
d. Separated
e. Divorced
f. Widowed

6. What is the highest level of education you completed?
a. GED/High school diploma
b. Some college
c. College
d. Postgraduate
e. Other

7. Please specify if you selected Other as your answer for question \#6.

8. What is your current job or occupation status?
a. Working full time (for income or as volunteer)
b. Working part time (for income or as volunteer)
c. Retired
d. Other

9. Please specify if you selected Other as your answer for question \#8. 
10. Do you have any current chronic medical illness? (cancer, arthritis, hypertension, etc.)
a. Yes
b. No

11. Please specify the illnesses if you selected "Yes" as your answer for question \#10.

12. Have you had any major medical procedures or surgeries that had life-threatening consequences OR consequences that could affect your daily functioning, health, or well-fare? (organ transplant, chemotherapy, joint replacement, dialysis, etc.)
a. Yes
b. No

13. Please specify if you selected "Yes" as your answer for question \#12.

14. Do you currently have advance directives? (Check all that apply)

Living will

Medical power of attorney

Combined living will and medical power of attorney

15. Do you have a medical order? (Check all that apply)

Do Not Resuscitate card

Physician Order for Scope of Treatment

16. In general, would you say your physical health is
a. Excellent
b. Very good
c. Good
d. Fair
e. Poor 


\section{Mini-IPIP}

Describe yourself as you generally are now, not as you wish to be in the future. Describe yourself as you honestly see yourself, in relation to other people you know of the same sex as you are, and roughly your same age. Indicate for each statement whether it is 1 . Strongly Agree, 2. Agree, 3. Neither Agree Nor Disagree, 4. Disagree or, 5. Strongly Disagree as a description of you.

IPIP011 I am the life of the party

IPIP021 I sympathize with others' feelings

IPIP031 I get chores done right away

IPIP041 I have frequent mood swings

IPIP051 I have a vivid imagination

IPIP061 I don't talk a lot

IPIP071 I am not interested in other people's problems

IPIP081 I often forget to put things back in their proper place

IPIP091 I am relaxed most of the time

IPIP101 I am not interested in abstract ideas

IPIP111 I talk to a lot of different people at parties

IPIP121 I feel others' emotions

IPIP131 I like order

IPIP141 I get upset easily

IPIP151 I have difficulty understanding abstract ideas

IPIP161 I keep in the background

IPIP171 I am not really interested in others

IPIP181 I make a mess of things

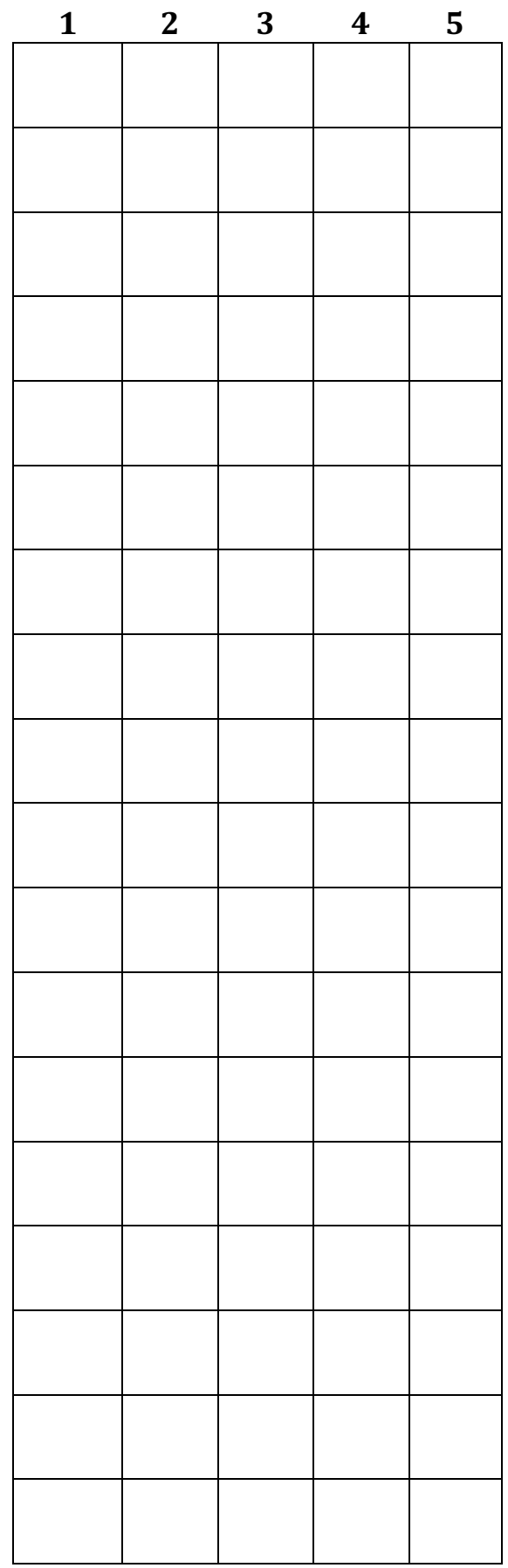


IPIP191 I seldom feel blue

IPIP201 I do not have a good imagination

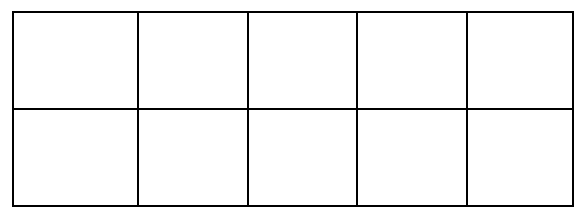




\section{CPS}

Please circle the statement below that most closely matches your preferred role in decisionmaking for medical treatments.

A. I prefer to make the final selection about which treatment I will receive.

B. I prefer to make the final selection of my treatment after seriously considering my doctor's opinion.

C. I prefer that my doctor and I share responsibility for deciding which treatment is best for me.

D. I prefer that my doctor make the final decision about which treatment will be used but seriously considers my opinion.

E. I prefer to leave all decisions regarding my treatment to my doctor. 


\section{Clinical Vignette}

The following information is hypothetical. The information should be considered when making a treatment decision.

You currently have a diagnosis of Chronic Obstructive Pulmonary Disease (COPD) and Stage 4 lung cancer. Your COPD causes shortness of breath, wheezing at times, and a chronic cough. For the past 6 months you have been receiving treatment at WVU Medicine for Stage 4 lung cancer. You have just learned that the cancer has metastasized, and has spread to other areas of your body. There is no further chemotherapy or radiation therapy that is likely to benefit you. Your oncologist suggested that you get your affairs in order and "look into" hospice. When asked, your physician said that she thought your estimated prognosis was one year or less. You talked about your situation with a neighbor who is a nurse. Your neighbor suggests that you complete a POST form so that your wishes for treatment are known and respected. Your physician agreed that it was appropriate to complete a POST form for you. Your physician asked you what your preferences were for orders on the POST form. 


\section{Physician Orders for Scope of Treatment (POST) - Medical Interventions}

The POST is a medical order form intended for people with serious health conditions. It is used to inform other providers about your treatment wishes.

The POST contains choices regarding how aggressive you want your medical treatment to be. There are three options to choose from. As part of the study, you will be using hypothetical information to select from one of the three levels of care.

The three levels are: Full Interventions, Limited Additional Interventions, and Comfort Measures.

Full Interventions involves all measures to keep you alive including use of CPR and a breathing machine in an intensive care unit. Limited additional interventions include intravenous fluids and heart monitoring but not intensive care. Patients will not receive CPR with this order. Comfort measures include treatments to preserve patient dignity without the use of machines. Patients with a comfort measures order will usually be kept comfortable at home or in a nursing home. They will not be transferred to the hospital unless they cannot be kept comfortable where they live. 


\section{DCS}

Considering your current knowledge of Medical Interventions and the information provided in the Clinical Vignette, please select what option you would choose:

D Full Interventions

D Limited Additional Interventions

D Comfort Measures

Please answer the following questions regarding your treatment decision:

\begin{tabular}{|l|c|c|c|c|c|}
\hline & $\begin{array}{c}\text { Strongly } \\
\text { Agree }\end{array}$ & Agree & $\begin{array}{c}\text { Neither } \\
\text { Agree } \\
\text { Nor } \\
\text { Disagree } \\
{[2]}\end{array}$ & Disagree & $\begin{array}{c}\text { Strongly } \\
\text { Disagree }\end{array}$ \\
\hline 1. I know which options are available to me. & D & D & D & D & D \\
\hline 2. I know the benefits of each option. & D & D & D & D & D \\
\hline 3. I know the risks and side effects of each option. & D & D & D & D & D \\
\hline 4. I am clear about which benefits matter most to me. & D & D & D & D & D \\
\hline $\begin{array}{l}\text { 5. I am clear about which risks and side effects matter } \\
\text { most to me. }\end{array}$ & D & D & D & D & D \\
\hline $\begin{array}{l}\text { 6. I am clear about which is more important to me (the } \\
\text { benefits or the risks and side effects). }\end{array}$ & D & D & D & D & D \\
\hline 7. I have enough support from others to make a choice. & D & D & D & D & D \\
\hline 8. I am choosing without pressure from others. & D & D & D & D & D \\
\hline 9. I have enough advice to make a choice. & D & D & D & D & D \\
\hline 10. I am clear about the best choice for me. & D & D & D & D & D \\
\hline 11. I feel sure about what to choose. & D & D & D & D & D \\
\hline 12. This decision is easy for me to make. & D & D & D & D & D \\
\hline 13. I feel I have made an informed choice. & D & D & D & D & D \\
\hline 14. My decision shows what is important to me. & D & D & D & D & D \\
\hline 15. I expect to stick with my decision. & D & D & D & D & D \\
\hline 16. I am satisfied with my decision. & D & D & D & D \\
\hline
\end{tabular}




\section{SWD}

Please answer the following questions about your decision for Medical Interventions. Please indicate to what extent each statement is true for you AT THIS TIME (circle one number for each statement).

\begin{tabular}{|c|c|c|c|c|c|}
\hline & $\begin{array}{l}\text { Strongly } \\
\text { Agree }\end{array}$ & Agree & $\begin{array}{l}\text { Neither } \\
\text { Agree or } \\
\text { Disagree }\end{array}$ & Disagree & $\begin{array}{l}\text { Strongly } \\
\text { Disagree }\end{array}$ \\
\hline $\begin{array}{l}\text { I was adequately informed about the } \\
\text { different treatments available }\end{array}$ & 1 & 2 & 3 & 4 & 5 \\
\hline $\begin{array}{l}\text { The decision I made was the best } \\
\text { decision possible for me personally }\end{array}$ & 1 & 2 & 3 & 4 & 5 \\
\hline $\begin{array}{l}\text { My decision was consistent with my } \\
\text { personal values }\end{array}$ & 1 & 2 & 3 & 4 & 5 \\
\hline $\begin{array}{l}\text { I expect to successfully carry out } \\
\text { (or continue to carry out) the } \\
\text { decision I made }\end{array}$ & 1 & 2 & 3 & 4 & 5 \\
\hline $\begin{array}{l}\text { I had as much input as I wanted in } \\
\text { the choice of treatment }\end{array}$ & 1 & 2 & 3 & 4 & 5 \\
\hline $\begin{array}{l}\text { I am satisfied with the decision that } \\
\text { was made about treatment }\end{array}$ & 1 & 2 & 3 & 4 & 5 \\
\hline $\begin{array}{l}\text { I am satisfied with the decision- } \\
\text { making process }\end{array}$ & 1 & 2 & 3 & 4 & 5 \\
\hline
\end{tabular}




\section{Knowledge Questionnaire}

Please circle the answer you think is correct. If you are not sure of an answer, please make an educated guess but do not guess randomly.

1. Cardiopulmonary Resuscitation (CPR) is used to:

a. Reduce chest pain following a heart attack.

b. Restart a person's heart after it has stopped beating.

c. Increase airflow after an asthma attack.

2. During CPR, about how many times is the person's chest pushed in each minute?
a. $100-120$
b. $80-100$

c. $60-80$

3. What percent of older adults (65+) are discharged from the hospital after receiving CPR?
a. More than $90 \%$
b. About $50 \%$
c. Less than $20 \%$

4. What percent of people with late stage cancers recover from CPR and are discharged from the hospital?
a. About $50 \%$
b. About $30 \%$
c. Less than $10 \%$

5. What percentage of people have ribs or breastbones broken while receiving CPR?
a. About $50 \%$
b. About $30 \%$
c. Less than $10 \%$

6. What percentage of people have brain damage after being resuscitated using CPR?
a. About $50 \%$
b. About $30 \%$
c. Less than $10 \%$

7. What medical procedure is used after a person is resuscitated using CPR, but is unconscious or unable to breathe on his or her own?
a. Cardioversion
b. Mechanical ventilation
c. Atrial Defibrilation

8. What is the default level of care for all West Virginians if they have not completed other orders for end of life care?
a. Full Interventions
b. Limited Additional Interventions
c. Comfort Measures

9. Patients who select prefer to avoid life support treatments and care in the ICU, but want easily addressed conditions to be treated?
a. Full Interventions
b. Limited Additional Interventions
c. Comfort Measures 
10. Which medical intervention order allows for use of intubation and mechanical ventilation?

a. Full Interventions

b. Limited Additional Interventions

c. Comfort Measures

11. What medical intervention order focuses on pain and symptom management but does not include treatments intended to extend life?

a. Full Interventions

b. Limited Additional Interventions

c. Comfort Measures

12. What is the "treatment plan" for people who select Limited Additional Interventions?

a. Provide full treatments including life support measures in the intensive care unit

b. Maximize comfort through symptom management

c. Provide basic medical treatments

13. What medical intervention order includes the use of all life-sustaining medical procedures?

a. Full Interventions

b. Limited Additional Interventions

c. Comfort Measures

14. Individuals who select are more likely THAN THOSE WHO SELECT OTHER OPTIONS to die outside of the hospital (e.g., home, nursing facility, assisted living).

a. Full Interventions

b. Limited Additional Interventions

c. Comfort Measures

15. Which medical intervention order provides CPR to a person who is in cardiac arrest?

a. Full Interventions

b. Limited Additional Interventions

c. Comfort Measures

16. Based on the intervention level you selected, would CPR be administered if your heart stopped beating?

a. Yes

b. No

17. Based on the intervention level you selected, would mechanical ventilation be used if you had difficulty breathing?

a. Yes

b. No

18. Based on the intervention level you selected, would you receive any treatment that had a goal to extend your life?

a. Yes

b. No 


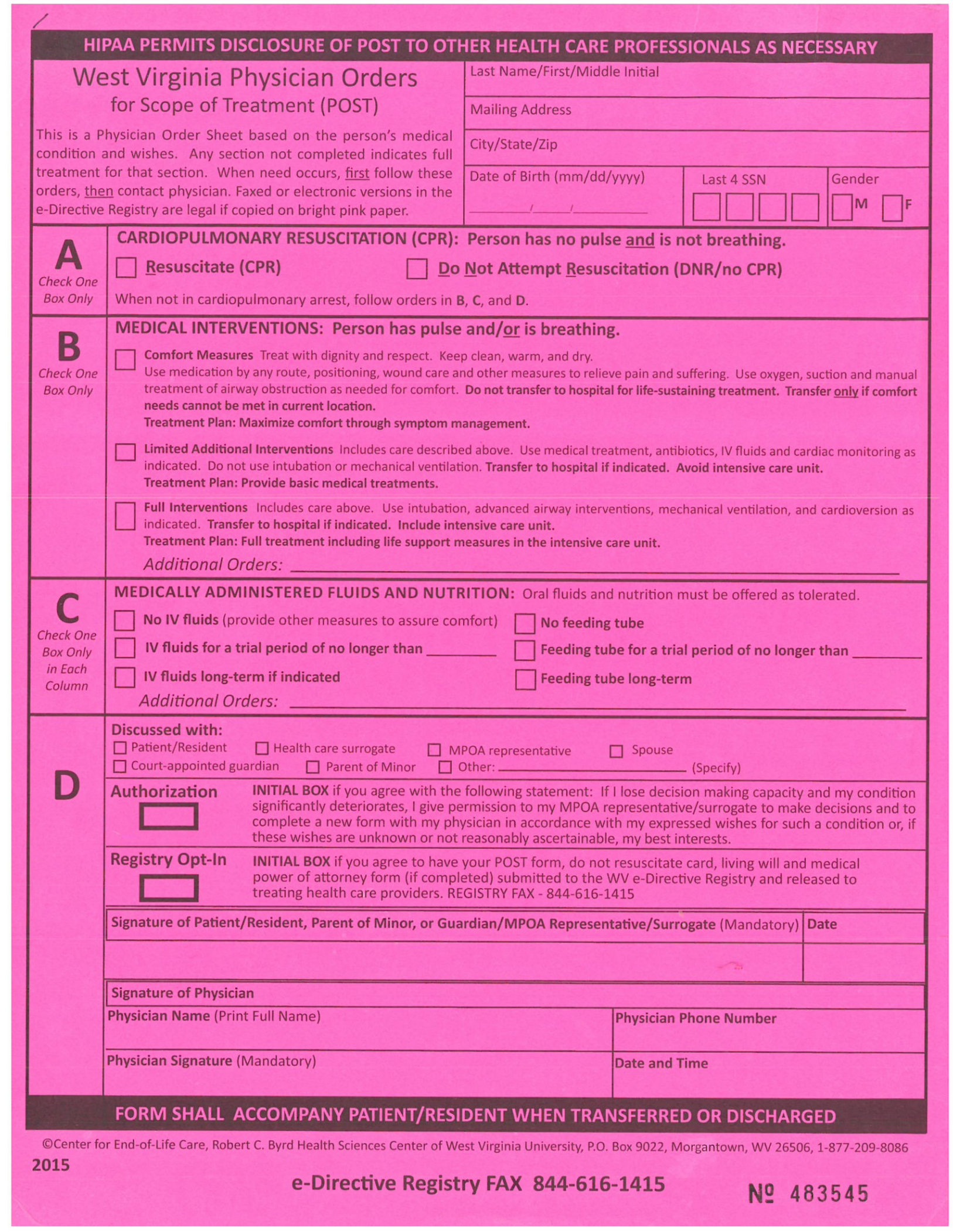




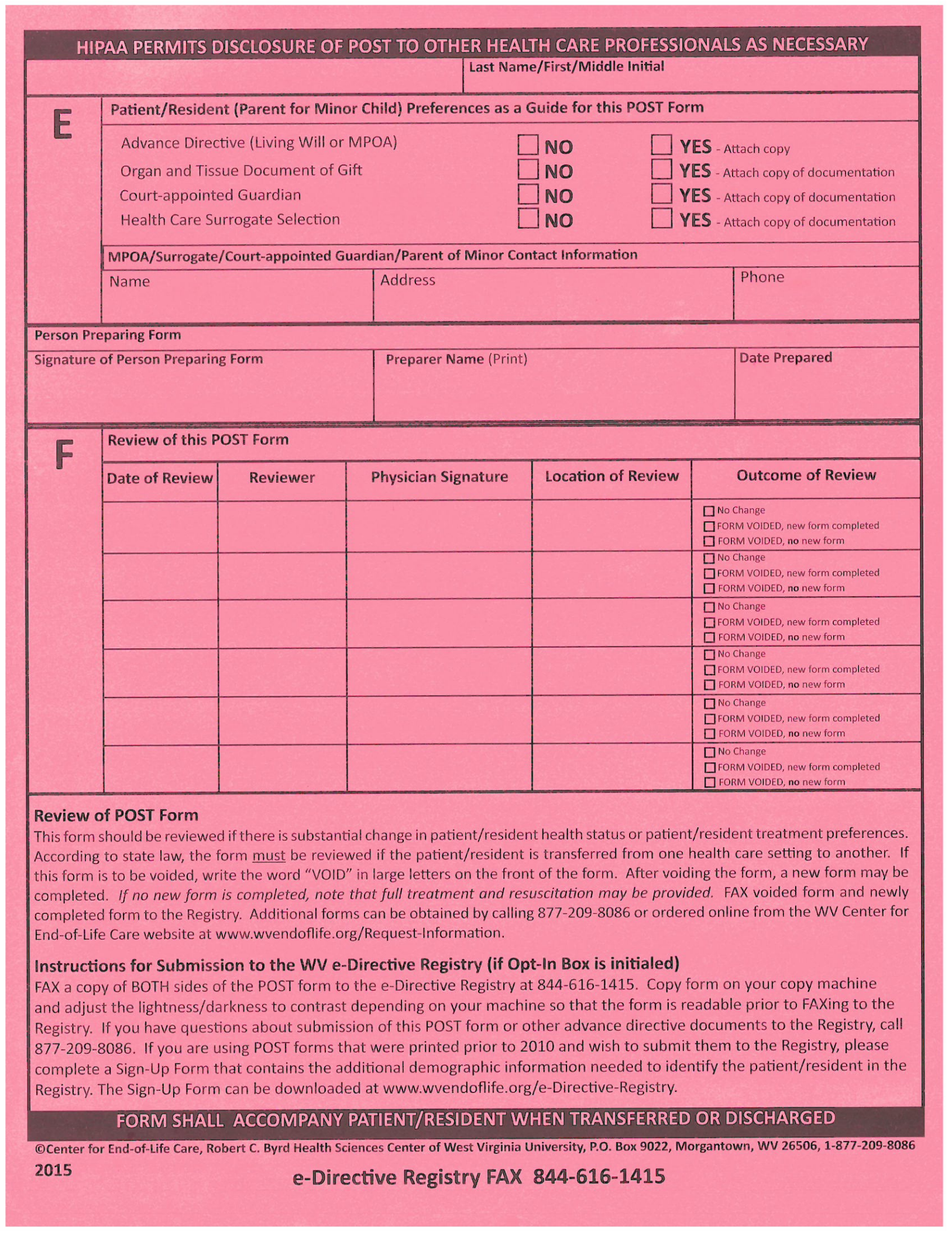




\section{Evaluation of Video Aid Questionnaire}

\begin{tabular}{|l|l|l|l|l|l|}
\hline & $\begin{array}{l}\text { Strongly } \\
\text { Agree }\end{array}$ & Agree & $\begin{array}{l}\text { Neither } \\
\text { Agree or } \\
\text { Disagree }\end{array}$ & Disagree & $\begin{array}{l}\text { Strongly } \\
\text { Disagree }\end{array}$ \\
\hline $\begin{array}{l}\text { The video aid makes clear the } \\
\text { decisions to be made }\end{array}$ & & & & & \\
\hline $\begin{array}{l}\text { The video aid presents an alternative } \\
\text { option for each decision }\end{array}$ & & & & & \\
\hline $\begin{array}{l}\text { The video aid provides risks/benefits } \\
\text { associated with alternative options }\end{array}$ & & & & & \\
\hline $\begin{array}{l}\text { The video aid provided probabilities } \\
\text { of outcomes associated with treatment } \\
\text { options }\end{array}$ & & & & & \\
\hline $\begin{array}{l}\text { The video aid helped to clarify } \\
\text { personal values that influence the } \\
\text { decisions }\end{array}$ & & & & & \\
\hline $\begin{array}{l}\text { The video aid did not appear to be } \\
\text { biased or slanted toward any } \\
\text { particular option }\end{array}$ & & & & & \\
\hline The video aid was helpful & & & & & \\
\hline $\begin{array}{l}\text { I would recommend the video aid to a } \\
\text { friend or family member }\end{array}$ & & & & & \\
\hline $\begin{array}{l}\text { Overall, I felt comfortable using the } \\
\text { video aid }\end{array}$ & & & & & \\
\hline
\end{tabular}

